Estudios Constitucionales, Año 10, No 1, 2012, pp. 65 - 116.

ISSN 0718-0195

Centro de Estudios Constitucionales de Chile Universidad de Talca

"El principio de proporcionalidad en la jurisprudencia del Tribunal Constitucional”

Rainer Arnold - José Ignacio Martínez Estay - Francisco Zúñiga Urbina

\title{
EL PRINCIPIO DE PROPORCIONALIDAD EN LA JURISPRUDENCIA DEL TRIBUNAL CONSTITUCIONAL (1)
}

\section{THE PRINCIPLE OF PROPORTIONALITY ON THE JURISPRUDENCE OF THE COnstitutional Court.}

RAINER ARNOLD

José IgNACIO MarTíNeZ EstaY

Francisco ZÚNIIGa URBINA ${ }^{(2)}$

zdmc@zdmcabogados.cl

RESUMEN: El presente texto se refiere al origen, desarrollo y significado del principio de proporcionalidad, de acuerdo a la evolución del mismo en la jurisprudencia, tanto a nivel de derecho comparado como en nuestro sistema jurídico.

El principio de proporcionalidad encuentra su origen en Alemania, siendo desarrollado por la jurisprudencia constitucional de ese país, para luego expandir su aplicación en el ámbito europeo, al sistema americano de derechos humanos y a los diversos paises de Latinoamérica. De esta forma, el trabajo examina el surgimiento y desarrollo en Europa del principio de proporcionalidad, y la aplicación del mismo que ha realizado la jurisprudencia del Tribunal Constitucional, de acuerdo a una exposición de las sentencias que se consideran más representativas al respecto.

ABSTRACT: This text refers to the origin, development and meaning of the principle of proportionality, according to its evolution in case law, both comparative law and in our legal system.

The principle of proportionality has its roots in Germany, being developed by the constitutional jurisprudence of this country, and then expand its application in Europe, the American system of human rights and the various Latin American countries. Thus, the paper examines the emergence and development in Europe the principle of proportionality and its application made by the jurisprudence of the Constitutional Court, considering a statement of the statements that are considered more representative in this regard.

PALABRAS CLAVE: Proporcionalidad; Jurisprudencia; Tribunal Constitucional; Derechos Fundamentales.

KEY WORDS: Proportionality; Jurisprudence; Constitutional Court; Fundamental Rights.

\footnotetext{
${ }^{1}$ Este trabajo es producto de la investigación llevada a cabo por sus autores en el marco del proyecto Fondecyt No 1100639 , "Los principios de razonabilidad y de proporcionalidad en la jurisprudencia del Tribunal Constitucional". Artículo recibido el 14 de marzo de 2012 y aprobado el 2 de mayo de 2012.

${ }^{2}$ Rainer Arnold, Profesor de Derecho Público, Catedrático Jean Monnet, Facultad de Derecho, Universidad de Regensburg, Alemania; José Ignacio Martínez Estay, profesor de Derecho Constitucional y Administrativo, Catedrático Jean Monnet, Facultad de Derecho, Universidad de los Andes, Chile; Francisco Zúñiga Urbina, profesor de Derecho Constitucional Universidad de Chile y Universidad Diego Portales, Chile. zdmc@zdmcabogados.cl
} 


\section{PRESENTACión}

Este trabajo es la continuación del titulado "El Principio de Razonabilidad en la Jurisprudencia del Tribunal Constitucional", publicado en Estudios Constitucionales año 9, No 1 (2011; 199-226), en el que se analizó la forma en que nuestro Tribunal Constitucional ha utilizado dicho principio como criterio de control de constitucionalidad. En aquella oportunidad advertimos que a partir de la Ley Fundamental de Bonn, y más concretamente de la jurisprudencia del Tribunal Constitucional alemán, se introdujo en el lenguaje constitucional un término distinto, pero que en cierta forma viene a reflejar la misma exigencia propia del principio de razonabilidad, a saber, que la producción de Derecho debe sujetarse a ciertos estándares que impidan o disminuyan al máximo la arbitrariedad. Ese es el origen de la idea de proporcionalidad, que se ha expandido no sólo por Europa, sino que también a nuestras latitudes, tanto desde el punto de vista doctrinario como jurisprudencial.

Sostuvimos entonces que si bien razonabilidad y proporcionalidad son conceptos parecidos, que apuntan al mismo objetivo de evitar la arbitrariedad, estricta y formalmente no son lo mismo, aunque existe una relación entre ambos principios, de género a especie. Ello porque la idea de razonabilidad abarca la proporcionalidad, siendo ésta una consecuencia o manifestación de aquélla. Mediante la proporcionalidad se puede llegar a determinar si una actuación estatal, y más precisamente si la intensidad de ésta, es o no jurídicamente la más adecuada para perseguir un determinado fin. Al respecto conviene tomar en consideración lo que señala con acierto Fernández a propósito del principio de igualdad. Ello porque una forma de saber si un acto es o no arbitrario y carente de razonabilidad, es determinar si existe proporcionalidad entre aquél y el fin que se persigue ${ }^{3}$.

En las siguientes líneas se analizará el origen, desarrollo y significado del principio de proporcionalidad. Para tal efecto se revisará su surgimiento en Alemania, la forma en que ha sido reconocido y desarrollado por la jurisprudencia constitucional de ese país, así como la expansión del mismo hacia la Unión Europea, el sistema europeo y el sistema americano de derechos humanos, y los países de Europa y Sudamérica. Por otra parte, se tratará de demostrar que si bien hay un ámbito en donde la aplicación de la proporcionalidad resulta no sólo adecuada, sino que además necesaria (control del exceso de poder), hay otro en el que esto resulta al menos discutible (criterio de solución de conflictos de derechos).

\footnotetext{
${ }^{3}$ FERNÁNDEZ (2001) 262-263. Como se verá más adelante, en algunas oportunidades nuestro TC ha usado la proporcionalidad como un mecanismo destinado a determinar si ha habido o no arbitrariedad en una norma.
} 
Finalmente se examinará la forma en que este principio ha sido recogido en la Constitución Chilena, cómo ha sido aplicado por la jurisprudencia de nuestro Tribunal Constitucional (TC), para finalmente extraer un listado de criterios de proporcionalidad emanados de ella.

\author{
II. EL PRINCIPIO DE PROPORCIONALIDAD: \\ ORIGEN, DESARROLLO, SIGNIFICADO Y EXPANSIÓN
}

\title{
A. Origen y desarrollo
}

Como lo hace presente Sapag, este principio es el equivalente europeo continental al principio de razonabilidad ${ }^{4}$. Pereira lo califica como "un principio de razonabilidad y sentido común"s. Su origen está en el derecho prusiano de policía, en donde la proporcionalidad cumplía una función orientativa respecto de las intervenciones en la libertad individual ${ }^{6}$. La jurisprudencia del Tribunal Superior Administrativo de Prusia (preussisches OVG) sostuvo que este principio era vinculante para el poder ejecutivo ${ }^{7}$, para lo cual acuñó el concepto de "prohibición de exceso", "como un criterio de control sobre los poderes discrecionales de la administración y como límite al ejercicio del poder de policía". Sin embargo, estas manifestaciones del principio de proporcionalidad se corresponden con una época en la que el constitucionalismo no respondía a los estándares actuales, ya que el legislador no estaba sometido a la Constitución, y por ende la proporcionalidad se aplicaba sólo al ejecutivo. Pero a su vez los actos de este último no fueron suficientemente justiciables, debido a que existían largos listados de materias exentas de control. Asimismo, no se otorgaba valor normativo directo a los derechos fundamentales, y el Estado de Derecho era concebido en un sentido más bien formal, basado en el principio de legalidad y no en el de constitucionalidad'.

\footnotetext{
${ }^{4}$ SAPAG (2008), 170.

${ }^{5}$ Pereira (2003), 4

${ }^{6}$ KRAFT (2007), 577-578. No obstante, algunos, como Bernal, sostienen que "el surgimiento del principio de proporcionalidad, como concepto propio del Derecho Público europeo, se remonta al contractualismo iusnaturalista de los tiempos de la Ilustración. Bernal (2007), 44.

${ }^{7}$ Ibid.

${ }^{8}$ Ibid., $170-171$.

${ }^{9}$ A partir de la Revolución francesa se asentó la idea de que el poder radicaba en el pueblo, el que jurídicamente éste hablaba a través de la ley. Por ende, no había ninguna otra norma que estuviese sobre ella. La Constitución era vista más bien como un texto más político que jurídico, sin valor jurídico vinculante, y como consecuencia de ello sin carácter justiciable.
} 
Pero desde la Ley Fundamental de Bonn de 1949, el Tribunal Constitucional Federal (TCF) desarrolló el concepto de la proporcionalidad con estrecha referencia a la naturaleza de los derechos fundamentales y al estado de derecho ${ }^{10}$. De acuerdo al TCF "se trata de un principio general de rango constitucional, inserto en la cláusula del estado de derecho que preside la actuación de todos los poderes públicos"11.

Ya en 1952, en la decisión de prohibir el partido SRP (extrema derecha), el TCF aplicó este principio, e hizo presente la obligación de la policía de ejecutar con medidas "adecuadas" la sentencia mediante la cual lo había declarado inconstitucional ${ }^{12}$. El Tribunal aplicaba así el principio de proporcionalidad a las actuaciones del Ejecutivo. Dos años después el TCF, al analizar la constitucionalidad de una ley electoral, extendió al legislador el principio de "proporcionalidad de la finalidad de la acción y la medida usada"13. Más tarde, en 1958, el Tribunal explica dogmáticamente el significado de este principio en la famosa sentencia sobre admisión limitada de farmacias, conocida como Apothekenurteil (de 11 de junio de 1958).

\section{B. Significado}

Como ya se adelantó, en esencia el principio de proporcionalidad apunta a la interdicción de actuaciones o intervenciones excesivas por parte de los poderes públicos, y a partir de la jurisprudencia del Tribunal Constitucional Federal (TCF), la proporcionalidad pasó a transformarse en un principio constitucional de protección de los derechos fundamentales. En virtud de él se "prohíbe que las acciones de los poderes públicos sean excesivas -Übermassverbot-y se establece la obligación de que estén contenidas dentro de sus propios límites"14. Por ende, se trata esencialmente de un principio destinado a proteger los derechos y libertades, que si bien no está escrito, el TCF entiende que está implícito en los fundamentos del sistema constitucional alemán.

Junto a ese significado esencial de la proporcionalidad, ésta ha sido entendida también por el TCF como un complemento a otros principios derivados del estado de derecho alemán, como el principio de determinación y precisión, la irretro-

\footnotetext{
${ }^{10}$ Pero antes que el TCF, el Tribunal Constitucional de Baviera se había referido explícitamente a tal principio.

${ }^{11}$ FernÁNDEZ (2008), 283.

${ }^{12}$ TCF sentencias vol. 2, p.1, 78/79 (sentencia del 23 de octubre 1952).

${ }^{13}$ TCF vol. 3, pp. 383, 399.

${ }^{14}$ Pereira (2003), 42.
} 
actividad de la ley penal, el principio ne bis in idem y el deber de protección de los derechos que pesa sobre todos los poderes públicos. Y por último, el TCF ha hecho también extensivo el principio de proporcionalidad a las relaciones entre el gobierno central y la administración local, como mecanismo de protección de las competencias de esta última. Todos estos aspectos serán desarrollados a continuación.

\section{La "teoria de las fases" (Stufentheorie)}

Como ya se dijo, en Alemania el principio de proporcionalidad está indefectiblemente vinculado a la protección de los derechos fundamentales. En la sentencia Apothekenurteil el TCF desarrolló por primera vez los fundamentos del principio de proporcionalidad como medio de atenuación o modulación de la intervención estatal en los derechos y libertades de las personas.

En concreto, el TCF elaboró en esta sentencia la "teoría de las fases" (Stufentheorie), como expresión específica de la proporcionalidad en el contexto de la libertad profesional del artículo $12 \mathrm{LF}^{15}$. El TCF subrayó la conexión de la libertad profesional con el desarrollo de la personalidad. La profesión de una persona no sólo tiene repercusiones sociales, sino que también sobre el propio individuo. Por eso el TCF diferencia entre el ejercicio de la profesión y la admisión a la profesión.

El ejercicio de la profesión tiene un impacto considerable en la vida social, y por eso su regulación legislativa es más estricta y exhaustiva que el acceso a una profesión. Ello porque la admisión a una profesión se relaciona con el desarrollo personal del individuo, mientras que el ejercicio de aquélla tiene más impacto en la sociedad que en el individuo. El TCF entendió que lo importante es poder acceder a una profesión, y no cómo debe ejercerla. Esta diferenciación es el fundamento para la gradación de la posible intervención del Estado, cuestión que es acorde a la concepción que la Constitución alemana tiene respecto del hombre: un ser libre dotado de personalidad autónoma, pero que a su vez no es alguien aislado, sino que miembro de una comunidad, y que está limitado por los derechos de otros. Todo esto implica que la intervención del poder público debe reducirse al mínimo indispensable. En esta perspectiva, la libertad del individuo es un principio, en tanto que la restricción de ésta es una excepción, y ello es a su vez el fundamento del principio de proporcionalidad. Éste conlleva la idea de que la intervención pública debe ser excepcional, lo que también implica un especial cuidado en cuanto a su intensidad y a su impacto respecto del individuo. Esta excepcionalidad exige una ponderación entre el interés público y el interés individual.

${ }^{15}$ TCF vol. 7, pp. 377, 397-413, con referencia explícita al principio de la proporcionalidad en página 407. 
En la mencionada sentencia el TCF diferencia tres fases: la primera comprendía el ejercicio de la profesión, cuestión en la que el legislador puede intervenir de manera más libre e intensa que en otras etapas. La intervención debe siempre perseguir una finalidad legítima de interés público. La segunda y la tercera fases se referían al acceso a la profesión, y el TCF entendió que tenían más impacto en el individuo y en el desarrollo de su personalidad. La segunda etapa comprendía requisitos subjetivos necesarios para poder acceder a una profesión, como por ejemplo haber pasado un examen o presentar ciertas habilidades para ser admitido en la profesión.

La tercera fase se refiere a requisitos objetivos, que no dependen de la persona sino que de la situación objetiva en que se desenvuelve. Ejemplo de ello es la legislación que limita el número de personas que pueden ejercer una cierta profesión (de taxistas, de farmacias, de restaurantes, etc.), limitación resultante de la situación social o económica. La prohibición de abrir en un lugar una segunda farmacia, que fue lo previsto por el legislador en el caso mencionado, tenía como fundamento la exigencia de proteger la salud pública. El legislador entendió que la apertura de otra farmacia en una localidad con poca población, podía poner en riesgo dicha protección, debido a que la competencia entre ellas podía conducir al incumplimiento de deberes importantes para con la salud de la población.

Las restricciones impuestas por el legislador deben estar sujetas a mayores exigencias en cuanto a los fines perseguidos por aquéllas. Así, en la primera fase cualquier interés público es suficiente para la regulación del ejercicio de una profesión. En la segunda y la tercera fases se requiere que el interés público sea importante para restringir el acceso a una profesión, mediante la fijación de requisitos subjetivos (segunda fase) y objetivos (tercera fase). El TCF entendió que para la fijación de estos requisitos debían considerarse como factores importantes de interés público a la salubridad pública, la seguridad pública, y en general las exigencias derivadas del orden público, etc. En resumen, de acuerdo al TCF la proporcionalidad se expresa en diversos grados de intervención correspondientes a diversas finalidades.

Pero junto a lo anterior, el TCF señaló que la proporcionalidad tiene además una segunda dimensión: la finalidad perseguida por el legislador debe ser cumplida en la fase más baja posible. En otros términos, la intervención del poder público no debe ir más allá de la intensidad mínima que sería necesaria para un cumplimiento eficaz de la finalidad perseguida, o lo que es lo mismo. Por ello el TCF entendió que el legislador debía establecer restricciones a la libertad profesional con el grado mínimo de intervención. Así, no sería constitucional y supondría una infracción de la proporcionalidad, que el legislador estableciera requisitos subjetivos para el acceso a la profesión, si la finalidad perseguida (que debe ser legítima) pudiera ser suficientemente cumplida con la fijación de los requisitos para el ejercicio de la profesión. En 
tal caso, el legislador no podría pasar a la segunda fase, sino que debería permanecer en la primera, que es la que requiere menos intensidad de intervención.

\section{Los requisitos de la proporcionalidad}

A partir de la sentencia Apothekenurteil, el principio de proporcionalidad se ha mostrado como un instrumento eficaz, flexible y pragmático para moderar la tensión entre el individuo y el poder público. La jurisprudencia del TCF lo ha utilizado muy frecuentemente y puede ser considerado como el concepto más importante de la dogmática de los derechos fundamentales y del Estado de derecho en Alemania ${ }^{16}$.

La jurisprudencia desarrollada por el TCF a partir de aquella sentencia, permite identificar cuatro requisitos que emanan del principio de proporcionalidad. Estos resultan aplicables a toda intervención en la libertad y propiedad de las personas por parte del poder público, sea del legislador, del Poder Ejecutivo o del Poder Judicial:

a) Debe perseguir una finalidad legítima.

b) Debe ser adecuada o idónea para la promoción (no necesariamente la realización) de dicho objetivo legítimo (geeignetheit o adecuación).

c) Debe ser necesaria, y entre varias alternativas de intervención debe preferirse la que afecte menos a los derechos involucrados (mínimo de intervención).

d) Debe ser proporcional en sentido estricto, es decir, la gravedad de la intervención ha de ser la adecuada al objetivo de la intervención. Por tanto los instrumentos y los medios aplicados deben justificarse en su grado de gravedad: la gravedad de las intervenciones debe ser proporcionada a la urgencia o necesidad de los objetivos. Si éstos no son urgentes o no son muy necesarios, los instrumentos utilizados deben ser de menor intensidad (relación zweck-mittel). Este último requisito parece ser el más importante para la protección de la libertad individual. Conlleva una ponderación entre el interés del individuo, manifestado en su derecho fundamental, y el interés público. Esta ponderación debe tener en cuenta la situación particular del individuo y, desde luego, no puede suponer la anulación o negación del derecho.

De la jurisprudencia del TCF se concluye que respecto de los tres primeros requisitos el legislador tiene un margen de discrecionalidad, que reduce el ámbito de control jurisdiccional. En concreto, sólo errores manifiestos podrían conducir a la

${ }^{16}$ TCF vol. 13, pp. 97, 104, 115; vol. 16, pp. 194, 202-203; vol. 17, pp. 108, 117; vol. 17, pp. 232, 242; vol. 19, pp. 342, 347-352; vol. 125, pp. 260, 278, 291, 316, 325, 356, 363, 366, etc. 
anulación de una norma legal por ser contraria al principio de proporcionalidad ${ }^{17}$. Con relación al cuarto requisito, el TCF ha sostenido que su cumplimiento implica fundamentar de manera clara las circunstancias subjetivas y objetivas relevantes.

\section{Proporcionalidad y estado de derecho}

En Alemania el principio de proporcionalidad no sólo ha servido para modular la intervención estatal en las libertades y derechos fundamentales, sino que además ha servido como complemento a otros principios derivados del estado de derecho, reconocido por los artículos 20 y 28.1 de la Constitución alemana. Así, el principio de determinación y de claridad normativa (Bestimmtheitsgebot), es frecuentemente vinculado al de proporcionalidad ${ }^{18}$. En tal sentido, una ley que permite a las autoridades intervenir en la libertad del individuo, en particular en el contexto de medidas de seguridad, debe determinar con precisión los requisitos y las condiciones de la intervención. Por supuesto no es posible evitar el uso de términos generales que deben ser concretizados por el ejecutivo en el caso concreto, pero resulta del estado de derecho y el principio de proporcionalidad obligan al legislador a concretizar las condiciones de la intervención lo más posible. Ello resulta especialmente delicado en el ámbito del Derecho penal, en el que es indispensable establecer en detalle y sin ambigüedad la descripción típica y la penalidad. Consecuencia de ello es que en materia penal se ha prohibido la interpretación por analogía. Asimismo, el artículo $103 \mathrm{LF}$, prevé el principio de irretroactividad penal y el de ne bis in idem ${ }^{19}$.

Por otra parte, en materia de seguridad la proporcionalidad y el Eetado de derecho conllevan la exigencia de que cualquier investigación que pudiera suponer una intervención grave en la libertad del individuo, sólo puede llevarse a cabo en caso de un peligro concreto, no meramente abstracto ${ }^{20}$.

A su vez, la proporcionalidad implica frecuentemente la observancia de ciertas reglas de procedimiento contempladas en la ley, destinadas a proteger la libertad de las personas. Se trata de una consecuencia de la dimensión objetiva de los derechos fundamentales, que conlleva el deber del legislador (y de otros órganos del Estado) de proteger activamente los valores protegidos por esos derechos fundamentales (Schutzpflicht). El legislador es obligado a cumplir este deber estableciendo reglas sustanciales, procedimentales y de organización que presten una protección sufi-

\footnotetext{
${ }^{17}$ V. TCF vol. 125 , p. 260 , en particular pp. 317 y 318

${ }^{18}$ TCF vol. 125, pp. 360, 328

${ }^{19}$ Ver ARnold, Rainer: Constitutions et droit pénal, Rapport allemand, XXVIe Table ronde internationale Aix-en-Provence 2010, pp. 95-108.

${ }^{20}$ TCF vol. 120 , pp. 378,388
} 
ciente a los derechos. La proporcionalidad se vincula con este deber porque es el medio para proteger al individuo de intervenciones excesivas ${ }^{21}$.

Por último, el Tribunal Constitucional alemán ha hecho también extensivo el principio de proporcionalidad a las relaciones entre el gobierno central y la administración local. En tal sentido, las potestades de esta última sólo pueden restringirse siempre que el objetivo sea legítimo, que la medida sea idónea y adecuada para alcanzarlo, y que de entre varias posibles medidas se adopte la menos restrictiva.

\section{C) La expansión del principio de proporcionalidad}

\section{El principio de proporcionalidad en la Unión Europea (UE)}

\section{a) La proporcionalidad como parte del proceso de constitucionalización de la UE}

La creación de las Comunidades europeas durante la década de los cincuenta del siglo pasado, implicó la transferencia de competencias internas de los Estados miembros a las instituciones comunitarias. Ese proceso continuó desarrollándose a lo largo de la segunda mitad del siglo XX, y en cierta forma continúa hasta hoy, ahora ya en el marco de la Unión Europea. Este proceso ha sido asimilar al de la construcción de una comunidad política, aunque inicialmente sin reconocimiento expreso de derechos fundamentales y de los elementos propios de un estado de derecho. Ello hizo necesario avanzar hacia un proceso de constitucionalización de la integración europea, lo que fue posible gracias a la jurisprudencia del Tribunal de Justicia de las Comunidades Europeas (TJ). Ella permitió reconocer y desarrollar principios generales ${ }^{22}$, derechos fundamentales ${ }^{23} \mathrm{y}$ los principios propios de un Estado democrático de derecho ${ }^{24}$, extraídos todos de las tradiciones constitucio-

${ }^{21}$ TCF vol. 120 , p. 274

${ }^{22}$ Sentencia Costa/Enel, de 15 de julio de 1964 (asunto 6/64), y sentencia Administration des finances de l'Etat/ Societé anonyme Simmenthal, de 9 de marzo de 1978 (asunto 106/77), ambas sobre el principio de primacía del derecho comunitario. Sentencia N.V. Algemene Transport-en Expeditie Onderneming Van Gend Loos/Administration Fiscale Néerlandaise, de 5 de febrero de 1963 (asunto 26/62), sobre el principio de efecto directo del Derecho comunitario. Los aspectos esenciales de estas sentencias pueden consultarse en Pereira et alii (2000).

${ }^{23}$ Sentencia Internationale Handelsgesellschaft mbH/Einfurh- und Vorratsstelle für Getreide und Futtermittel, de 17 de diciembre de 1970 (asunto 11/70), y sentencia Nold, Koblen-und BaustoffgroBhandlung/Comisión, de 14 de mayo de 1974 (asunto 4/73), que declaran que los instituciones europeas deben respetar los derechos fundamentales reconocidos en la Convención Europea de Derechos Humanos y en las tradiciones constitucionales comunes. Los aspectos esenciales de estas sentencias pueden consultarse en Pereira et alii (2000).

${ }^{24}$ Sentencia S.A. Roquette Frères/Consejo, de 29 de octubre de 1980 (asunto 138/79), que en virtud del principio democrático reconoce la necesidad de participación del Parlamento Europeo en la adopción de normas comunitarias. También sentencia Parti Ecologiste-"Les verts"/Parlamento Europeo, de 23 de abril de 1986 (asunto 294/83), en la que el TJ declara que en la Unión Europea rige un Estado de Derecho. Los aspectos esenciales de estas sentencias pueden consultarse en Pereira et alii (2000). 
nales comunes de los países miembros, así como de la Convención Europea de Derechos Humanos.

b) El principio de proporcionalidad y la restricción de las libertades y de los derechos fundamentales. Una de las consecuencias de dicha jurisprudencia fue la adopción del principio de proporcionalidad, entendido esta vez como un mecanismo destinado a moderar las restricciones que adoptasen los Estados respecto de alguna de las libertades fundamentales del derecho comunitario (libre circulación de personas, libre circulación de bienes, libre circulación de capitales y libre circulación de servicios). La jurisprudencia del $\mathrm{TJ}$ ha llevado a entender que las restricciones a estas libertades sólo pueden darse si resultan indispensables para el cumplimiento de una finalidad legítima. Pero además el TJ ha sostenido que el principio de proporcionalidad resulta aplicable para la protección de los derechos fundamentales, como ocurrió por ejemplo en el caso $\mathrm{Hauer}^{25}$, en el que se señaló que las restricciones al derecho de propiedad debían respetar los límites de la proporcionalidad.

Sin embargo, el principio de proporcionalidad hoy no tiene sólo un sustento jurisprudencial, sino que además de tipo normativo. Y es que el año 2000 la Carta de los derechos fundamentales de la UE recogió en su artículo 52.1 el principio de proporcionalidad como mecanismo de resguardo de los derechos y libertades, tal y como lo había hecho anteriormente la jurisprudencia del TJ. Esta norma señala que el ejercicio de los derechos y libertades reconocidos en la Carta podría limitarse siempre y cuando las limitaciones "sean necesarias y respondan efectivamente a objetivos de interés general reconocidos por la Unión o a la necesidad de protección de los derechos y libertades de los demás" 26 .

Todo lo anterior revela la notable influencia alemana en la adopción del principio de proporcionalidad como medio de protección de los derechos y libertades en el ámbito de la UE27.

c) El principio de proporcionalidad como límite al ejercicio de las competencias de la UE. El principio de proporcionalidad no sólo ha servido como mecanismo de

\footnotetext{
${ }^{25}$ Sentencia de 13 de diciembre de 1979 (asunto 44/79). Esta jurisprudencia ha sido reiterada, por ejemplo, en la sentencia Wachauf de 13 de Julio de 1989 (asunto 5/88).

${ }^{26}$ El art. II-112.1 del fallido Tratado Constitucional de la Unión Europea, disponía que las limitaciones al ejercicio de los derechos sólo podían introducirse "respetando el principio de proporcionalidad, cuando sean necesarias y respondan efectivamente a objetivos de interés general reconocidos por la Unión o a la necesidad de protección de los derechos y libertades de los demás".

${ }^{27}$ Pereira Menaut sostiene que el artículo 52.1 de la Carta es de influencia alemana. La Convención que la elaboró por encargo del Consejo Europeo de Colonia (3 y 4 de junio de 1999), "fue presidida por Roman Herzog, antiguo Presidente de la República Federal Alemana y del Tribunal Constitucional alemán. Poco podremos extrañarnos, entonces, de que la Carta sea una criatura alemana;...”. Pereira (2011), 148. Pereira destaca también la influencia alemana en la jurisprudencia del TJ. Ibíd., 765.
} 
protección de las libertades económicas y de los derechos fundamentales, sino que además tiene una dimensión institucional, en el sentido de que es un medio destinado a limitar el ejercicio de las potestades de la UE, en resguardo de las de los estados miembros. En tal sentido el principio de proporcionalidad juega también un rol de "principio constitucional", y supone una restricción a las potestades de las instituciones de la Unión, que implica ponderar si las medidas aplicadas o implementadas son adecuadas para la consecución de los fines para los que se dictaron ${ }^{28}$.

Por eso la jurisprudencia del TJ comenzó a aplicar el principio de proporcionalidad con el fin de determinar si las instituciones habían ejercido adecuadamente sus competencias, sin invadir las propias de los Estados. Ello le llevó a afirmar la necesidad de que las actuaciones comunitarias debían ser las adecuadas para la realización del objetivo perseguido, sin ir más allá de lo estrictamente necesario para alcanzarlo ${ }^{29}$.

El reconocimiento jurisprudencial del principio de proporcionalidad como mecanismo de limitación del ejercicio de las potestades de la Unión, llevó después a su consagración normativa en el artículo 3B del Tratado de la Comunidad Europea (más tarde artículo 5), y hoy en el artículo 5.4 del Tratado de la Unión Europea (TUE). De acuerdo a esta norma "en virtud del principio de proporcionalidad, el contenido y la forma de acción de la Unión no excederán de lo necesario para alcanzar los objetivos de los Tratados". En otras palabras, la dimensión institucional de la proporcionalidad obliga a las instituciones a ejercer sus competencias exclusivamente para el cumplimiento de las finalidades propias de la $\mathrm{UE}^{30}$.

\section{El principio de proporcionalidad en la Convención Europea de Derechos} Humanos (CEDH) y en la Convención Interamericana de Derechos Humanos

a) El principio de proporcionalidad en la Convención Europea de Derechos Humanos. El principio de proporcionalidad ha sido recogido por el Sistema Europeo de Derechos Humanos (SEDH), aunque en menor medida que en Derecho de la UE. La diferencia radica en que así como en éste existe una norma que reconoce de manera expresa este principio (art. 5 del Tratado de la UE), y otra de la que se deduce como criterio general (artículo 52.1 de la Carta de los derechos fundamentales de la UE), en el sistema europeo de derechos humanos no existen normas similares.

\footnotetext{
${ }^{28}$ LenaerTS y VAN Nuffel (1999), 106.

${ }^{29}$ Sentencia Rau/Comunidad Económica Europea, de 11 de marzo de 1987 (asuntos 279, 280, 285 y 286/84). También sentencia de 28 de junio de 1990 (asunto C-174/89, "caso de la Mantequilla”), y sentencia de 5 de octubre de 1994 (asunto C-280/93, "caso de los plátanos”).

${ }^{30}$ Acerca del principio de proporcionalidad como criterio de atribución competencial en la Unión Europea puede consultarse también, Linde (2006), 44-49. También IsAAC (2000), 76.
} 
Además, algunos sostienen que, a diferencia de lo sucedido en la UE, en el ámbito del SEDH no es tan clara la influencia alemana en la adopción de este principio $^{31}$. De hecho agregan que su fundamento estaría más bien en el propio Derecho Internacional Público, en concreto, en el art. 29.2 de la Declaración Universal de los Derechos del Hombre de 1948, que implícitamente lo contiene al señalar que las limitaciones a los derechos fijadas por el legislador sólo pueden tener por finalidad "asegurar el reconocimiento y el respeto de los derechos y libertades de los demás, y de satisfacer las justas exigencias de la moral, del orden público y del bienestar general en una sociedad democrática"32. En cualquier caso, si bien la Convención Europea de Derechos Humanos no tiene una cláusula general del mismo tenor, puede sostenerse con certeza que la proporcionalidad está implícita en sus artículos 8 al 11. Esos preceptos determinan con claridad que las intervenciones al derecho al respeto a la vida privada y familiar (artículo 8), a la libertad de pensamiento, de conciencia y de religión (artículo 9), a la libertad de expresión (artículo 10) y a la libertad de reunión y de asociación (artículo 11), sólo son admisibles en la medida que sean necesarias en una sociedad democrática para el cumplimiento de los fines delineados en esos artículos ${ }^{33}$.

En virtud de lo anterior, la Corte Europea de Derechos Humanos (CEDH) ha adoptado el principio de proporcionalidad como un estándar para analizar los conflictos entre "los derechos de la Convención y el interés del gobierno en la consecución de bienes colectivos" 34 . Y precisamente lo ha hecho a la hora de resolver casos en los que han estado en juego los derechos recién mencionados. Así ha ocurrido, por ejemplo, en los casos Niemietz con Alemania ${ }^{35}$, Valenzuela Contreras con España ${ }^{36}$, Pretty con Reino Unido ${ }^{37}$, Von Hannover con Alemania ${ }^{38}$ (artículo 8 de la Convención); Kokkinakis con Grecia ${ }^{39}$, Hassan y Tchaouch con Bulgaria ${ }^{40}$, Leyla Sahin con

\footnotetext{
${ }^{31}$ Christoffersen (2009), 34-35. No obstante, Stone y Keller sostienen que la doctrina alemana de la proporcionalidad sí ha inspirado a la Corte Europea de Derechos Humanos. Stone y Keller (2008), 10.

${ }^{32}$ Christoffersen (2009), 37.

${ }_{33}$ Sobre el principio de proporcionalidad en la Convención Europea de Derechos Humanos ver McBride (1999), 23-35. También Christoffersen (2009).

${ }^{34}$ STONe y Keller (2008), 24.

${ }^{35}$ Sentencia de 6 de diciembre de 1992 (asunto 13710/88).

${ }^{36}$ Sentencia de 30 de julio de 1998 (asunto 58/1997/842/1048).

${ }^{37}$ Sentencia de 29 de abril de 2002 (asunto 2346/02).

${ }^{38}$ Sentencia de 24 de junio de 2004 (asunto 59320/00) y sentencia de 7 de febrero de 2012 (asuntos 40660/08 y 60641/08).

${ }^{39}$ Sentencia de 25 de mayo de 1993 (asunto 14307/88).

${ }^{40}$ Sentencia de 26 de octubre de 2000 (asunto 30985/96).
} 
Turquía ${ }^{41}$, Lautsi con Italia ${ }^{42}$ (artículo 9 de la Convención); Handyside con Reino Unido $^{43}$, Lingens con Austria ${ }^{44}$, Otto Preminger-Institut con Austria ${ }^{45}$, Wingrove con Reino Unido ${ }^{46}$, Fressoz y Roire con Francia ${ }^{47}$, Fikret Cetin con Turquid ${ }^{48}$, Mestri con Italia $^{49}$ (artículo 10 de la Convención); Ezelin con Francia ${ }^{50}$, Partido Comunista Unificado de Turquia y otros con Turquia ${ }^{51}$, Chassagnou y otros con Francia ${ }^{52}$, r Refah Partisi y otros con Turquía ${ }^{33}$ (artículo 11 de la Convención).

b) El principio de proporcionalidad en la Convención Interamericana de Derechos Humanos. Al igual que en la Convención Europea, en el Pacto de San José de Costa Rica no existe una norma que contemple expresamente este principio. Pero como señalan Quiroga y Nash, la jurisprudencia de la Corte Interamericana de Derechos Humanos (CIDH) sí lo ha recogido, al entender que está implícito en la expresión "necesaria en una sociedad democrática" ${ }^{4}$, parámetro utilizado en la Convención para modular la restricción de algunos derechos y libertades ${ }^{55}$. En tal sentido resulta emblemática la Opinión Consultiva $5 / 85^{56}$, en la que la Corte hizo suya la opinión de su símil europea respecto de dicha expresión. En concreto la $\mathrm{CIDH}$ "sostuvo que en el sistema interamericano la restricción (i) debe responder a la 'existencia de una necesidad social imperiosa', es decir, debe estar orientada 'a satisfacer un interés público imperativo'; (ii) entre varias opciones para alcanzar este objetivo 'debe escogerse aquella que restrinja en menor escala el derecho

${ }^{41}$ Sentencia de 10 de noviembre de 2005 (asunto 44774/98).

${ }^{42}$ Sentencia de 18 de marzo de 2011 (asunto 30814/06).

${ }^{43}$ Sentencia de 7 de diciembre de 1976 (asunto 5493/72).

${ }^{44}$ Sentencia de 8 de julio de 1986 (asunto 5493/72).

${ }^{45}$ Sentencia de 20 de septiembre de 1994 (asunto 13470/87).

${ }^{46}$ Sentencia de 25 de noviembre de 1996 (asunto 19/1995/525/611).

${ }^{47}$ Sentencia 21 enero de 1999 (asunto 29183/95).

${ }^{48}$ Sentencia de 13 de febrero de 2003 (asunto 24829/03).

${ }^{49}$ Sentencia de 17 de febrero de 2004 (asunto 39748/98).

${ }^{50}$ Sentencia de 26 de abril de 1991 (asunto 11800/85).

${ }^{51}$ Sentencia de 13 de enero de 1998 (asunto 133/1996/752/951).

${ }^{52}$ Sentencia de 29 de abril de 1999 (asuntos 25088/94, 28331/95 y 28443/95).

${ }^{53}$ Sentencia de 13 de febrero de 2003 (41340/98, 41342/98, 41343/98 y 41344/98).

${ }^{54}$ Quiroga y Nash (2007), 34.

${ }^{55}$ Artículo 15, sobre derecho de reunión, artículo 16 sobre libertad de asociación, artículo 22 sobre derecho de circulación y de residencia.

${ }^{56}$ De 13 de noviembre de 1985, sobre la colegiación obligatoria de periodistas (arts. 13 y 29 Convención Americana sobre Derechos Humanos), solicitada por el Gobierno de Costa Rica. 
protegido', y (iii) la restricción debe ser 'proporcionada al interés que la justifica y ajustarse estrechamente al logro de ese legítimo objetivo'. Esta interpretación constante de la expresión podría resumirse diciendo que la restricción debe ser (i) conducente para conseguir proteger el valor que se puede proteger mediante la restricción de ese derecho particular; (ii) debe ser proporcional, es decir, en la medida estrictamente necesaria para conseguir el fin perseguido; y (iii) no debe haber otra alternativa para conseguir el fin que restringir ese derecho, lo que implica que, si la hay, debe emplearse esa alternativa y no la restricción" ${ }^{\text {" }}$.

Por otra parte, en la Opinión Consultiva 8/8758, de 30 de enero de 1987, la Corte volvió a utilizar la idea de proporcionalidad, al señalar que la posibilidad de suspender garantías que contempla el artículo 27.1 de la Convención (considerando 22) la licitud de las medidas que se adopten depende, entre otras cosas, "del carácter, intensidad, profundidad y particular contexto de la emergencia, así como de la proporcionalidad y razonabilidad que guarden las medidas adoptadas respecto de ella".

Lo interesante es que la $\mathrm{CIDH}$ ha hecho extensivo el principio de proporcionalidad no sólo a aquellos casos vinculados a los derechos en cuya configuración la Convención utiliza la expresión "necesaria en una sociedad democrática", sino que también a otros. Así ha ocurrido por ejemplo con relación al derecho a la libertad personal (artículo 7) ${ }^{59}$, las garantías judiciales (artículo 8) ${ }^{60}$, protección de la honra y de la dignidad ${ }^{61}$, libertad de expresión (artículo 13) ${ }^{62}$, derecho de circulación y de residencia (artículo 22) ${ }^{63}$ derechos políticos (artículo 23) ${ }^{64}$, protección judicial (artículo 25) ${ }^{65}$

${ }^{57}$ Quiroga y Nash (2007), 34-35.

${ }^{58}$ de 30 de enero de 1987, sobre el habeas corpus bajo suspensión de garantías (arts. 27.2, 25.1 y 7.6 Convención Americana sobre Derechos Humanos), solicitada por la Comisión Interamericana de Derechos Humanos.

${ }^{59}$ Caso Usón Ramírez v. Venezuela, sentencia de 20 de noviembre de 2009.

${ }^{60}$ Caso Kimel v. Argentina, sentencia de 2 de mayo de 2008; caso Usón Ramírez v. Venezuela, sentencia de 20 de noviembre de 2009; caso López Mendoza v. Venezuela, sentencia de 1 de septiembre de 2011.

${ }^{61}$ Caso Kimel v. Argentina, sentencia de 2 de mayo de 2008.

${ }^{62}$ Caso Kimel v. Argentina, sentencia de 2 de mayo de 2008; caso Usón Ramírez v. Venezuela, sentencia de 20 de noviembre de 2009.

${ }^{63}$ Caso Ricardo Canese v. Paraguay, Sentencia de 31 de agosto de 2004.

${ }^{64}$ Caso Castañeda Gutman v. Estados Unidos Mexicanos, sentencia de 6 de agosto de 2008; caso López Mendoza v. Venezuela, sentencia de 1 de septiembre de 2011.

${ }^{65}$ Caso Castañeda Gutman v. Estados Unidos Mexicanos, sentencia de 6 de agosto de 2008; caso López Mendoza v. Venezuela, sentencia de 1 de septiembre de 2011; caso Usón Ramírez v. Venezuela, sentencia de 20 de noviembre de 2009. 


\section{La adopción del principio de proporcionalidad en los ordenamientos juridicos} nacionales europeos. La adopción del principio de proporcionalidad en la UE y en el SEDH ha influido en la adopción de este principio por los ordenamientos jurídicos nacionales de los estados europeos. Este proceso ha sido seguido por la profundización y desarrollo de este principio en el ámbito nacional, sobre todo mediante la labor de los jueces. Al respecto es posible observar una clara influencia de la jurisprudencia alemana en la de otros países de Europa, aunque adaptándose a cada cultura constitucional. Y así, por ejemplo, en Francia el principio de "proportionnalité" es bien conocido, y ha sido desarrollado por la jurisprudencia del Conseil Constitutionne ${ }^{166}$. Lo mismo ha ocurrido con la jurisprudencia de los tribunales constitucionales de Bélgica ${ }^{67}$, Polonia ${ }^{68}$ y España ${ }^{69}$, por mencionar algunos.

Sin embargo en Gran Bretaña la proporcionalidad en principio no resulta aplicable al legislador, en virtud del principio de soberanía del Parlamento. En teoría él excluye la posibilidad de ejercer control de constitucionalidad de las leyes, y por ende impide la primacía de la proporcionalidad sobre el legislador. No obstante, las cosas han cambiado de manera radical a contar de la entrada en vigor en el año 2000 de la Human Rights Act, mediante la cual se incorporó al Derecho interno británico la Convención Europea de Derechos Humanos. Ella se ha transformado en un instrumento que permite a los jueces controlar la actuación de todos los poderes públicos, incluido el legislador ${ }^{70}$, y uno de los parámetros que ofrece es precisamente el principio de proporcionalidad ${ }^{71}$, que como se vio antes, ha sido aplicado por la CEDH.

4. La adopción del principio de proporcionalidad en los ordenamientos jurídicos sudamericanos. En Sudamérica también ha penetrado este principio. En Brasil la Constitución federal no lo reconoce expresamente, pero en la doctrina se entiende que o bien "es una norma constitucional no escrita inherente al aparato jurídico del Estado Democrático de Derecho", o bien deriva "de otros principios, como el del

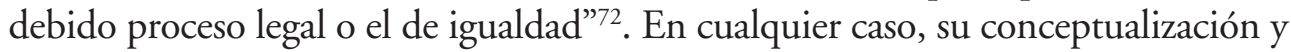

\footnotetext{
${ }^{66}$ A modo ejemplar puede consultarse la Sentencia del Conseil Constitutionnel de 21 de febrero 2008. Ver también GuilLENCHMidT (2010), 27-34.

${ }^{67}$ Por ejemplo sentencia 23/89, de 13 de octubre de 1989. Esta sentencia puede consultarse en Bon, P. y Maus, D. (2008), 238.

${ }^{68}$ Por ejemplo sentencia 11/98 de 2000, de 12 de enero de 2000. Esta sentencia puede consultarse en BoN, P. y Maus, D. (2008), 147.

${ }^{69}$ Por ejemplo STC 154/2002, de 18 de Julio de 2002. Esta sentencia puede consultarse en Bon, P. y MaUs, D. (2008), 157 .

${ }^{70}$ Elliot (2000), 269.

${ }^{71}$ Thomas (2000), 103-104; Arancibia (2010), 297;

${ }^{72}$ Ramos (2006), 669.
} 
aplicación es también de influencia alemana ${ }^{73}$, y la jurisprudencia brasileña lo ha plasmado en sus fallos, aunque muchas veces sin referirse expresamente a él $\mathrm{l}^{74}$.

En Colombia, si bien su Constitución no hace referencia expresa a él, su jurisprudencia sí lo ha recogido y desarrollado, y como señala Nogueira, "la Corte Constitucional colombiana ha desarrollado en su jurisprudencia al principio de proporcionalidad, siendo una de las jurisdicciones constitucionales que mejor uso han hecho del test de proporcionalidad", bajo una clara influencia alemana ${ }^{75}$. Por su parte en Perú, el artículo 200.6 de la Constitución peruana se refiere al principio de proporcionalidad como criterio judicial de revisión de los actos impugnados a través de estas acciones ${ }^{76}$, y ha sido aplicado por el Tribunal Constitucional peruano ${ }^{77}$. Sin embargo, en Argentina la Corte Suprema ha acudido más bien al principio de razonabilidad para el control del exceso de poder, tal y como ocurre en Estados Unidos ${ }^{78}$.

\section{III. ¿PROPORCIONALIDAD=PONDERACIÓN DE DERECHOS?}

\section{A. Proporcionalidad, conflictos o colisiones de derechos y ponderación}

A partir de la doctrina de Robert Alexy ${ }^{79}$, se ha extendido con gran influencia la idea de que los derechos y libertades pueden colisionar, y que la forma de solucionar esta clase de problemas es acudiendo a la proporcionalidad y a la ponderación entre los derechos en conflicto ${ }^{80}$. Como se sabe, Alexy asume que las normas de derechos fundamentales pueden clasificarse en reglas y principios, distinción que él califica de "clave para la solución de problemas centrales de la dogmática de los

\footnotetext{
${ }^{73}$ Ibid.

${ }^{74}$ Sobre la forma en que ha sido aplicado por los tribunales brasileños, en especial el Supremo Tribunal Federal, ver Ramos (2006), 679-683.

75 Nogueira (2010), 361-362.

${ }^{76}$ La norma señala: "Cuando se interponen acciones de esta naturaleza en relación con derechos restringidos o suspendidos, el órgano jurisdiccional competente examina la razonabilidad y la proporcionalidad del acto restrictivo. No corresponde al juez cuestionar la declaración del estado de emergencia ni de sitio".

${ }^{77}$ Nogueira (2010), 362.

${ }^{78}$ SAPAG (2008), 162, nota 13.

${ }^{79}$ Alexy (2007).

${ }^{80}$ Una obra de especial relevancia que refleja la influencia de Alexy en Hispanoamérica es el monumental trabajo de Bernal (2007), que a su vez también ha influido en buena parte de la doctrina hispanoamericana. El más reciente trabajo que refleja claramente lo anterior es "El principio de proporcionalidad en la interpretación jurídica", que recoge trabajos de los propios Alexy y Bernal, además de otros ocho autores; CARBOnell (2010). Ello sin perjuicio de que recientes trabajos de derecho constitucional chileno recogen también esta doctrina. A modo de ejemplo ver BASSA (2009), 70-75;
} 
derechos fundamentales", y "uno de los pilares fundamentales de la teoría de los derechos fundamentales" ${ }^{21}$. De acuerdo a esta distinción, "las reglas son normas que sólo pueden ser cumplidas o no" 82 , en tanto que los principios "son normas que ordenan que algo sea realizado en la mayor medida posible, dentro de las posibilidades reales existentes" ${ }^{\prime 3}$. Una consecuencia de estas características de los principios es que, dada su formulación genérica, no es posible entender el alcance que tiene el derecho que contiene ${ }^{84}$.

Por otra parte, tanto las reglas como los principios pueden entrar en conflicto (reglas) o colisionar (principios), lo que ocurriría cuando "dos normas, aplicadas independientemente, conducen a resultados incompatibles, es decir, a dos juicios

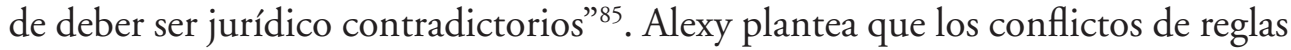
se solucionan "mediante la introducción en una de las reglas de una cláusula de excepción que elimine el conflicto o mediante la declaración de que por lo menos

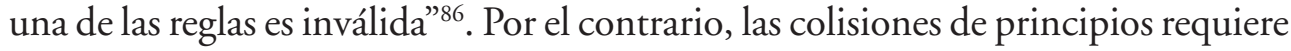
como solución que "uno de los dos principios tiene que ceder ante el otro", lo que implica que en cada caso concreto habrá que determinar cuál pesa más ${ }^{87}$. Ello conduce inevitablemente a ponderar o pesar los derechos, o, como dice Bertelsen, supone "contrapesar los bienes jurídicos en pugna -en nuestro análisis, los derechos fundamentales que colisionan- de acuerdo con las circunstancias del caso, para determinar cuál es más importante en el supuesto y cuál debe rendirse" 88 .

Son varios los problemas que plantea esta doctrina ${ }^{89}$. Entre otros pueden mencionarse los siguientes:

\footnotetext{
${ }^{81}$ Alexy (2007), 63.

${ }^{82}$ Ibid., 68.

${ }^{83}$ Por eso Alexy califica a los principio como "mandatos de optimización". Ibid., 67-68.

${ }^{84}$ Bertelsen (2010), 49.

${ }^{85}$ AleXy (2007), 69.

${ }^{86}$ Ibid.

${ }^{87}$ Ibid., 71.

${ }^{88}$ BERTELSEN (2010), 41-42. Bertelsen nos aclara que esta no es la única forma de hacer ponderación, sino que se trata de lo que se denomina el "balancing estricto o ad hoc balancing", que es justamente la que persigue determinar qué derecho pesa más en un caso concreto de colisión con otro. Junto a este método de ponderación existe también el denominado balancing en sentido amplio, en el que "un valor constitucional se contrapone a otros valores en pugna siendo este contrapeso en abstracto el que determina el contenido de la nueva norma subconstitucional aplicable".

${ }^{89}$ Buena parte de los problemas que aquejan a la doctrina de ponderación o balancing son abordados por BERTELSEN (2010), 49-52. En el presente trabajo no se tratan todos, sino que aquellos que hemos considerado más complejos.
} 


\section{Identificación de los derechos con las normas que los contemplan}

El primer problema es que aquella doctrina implica asumir que derechos y normas son lo mismo, por lo que obviamente los conflictos o colisiones entre normas son a su vez conflictos o colisiones entre derechos. Pero no es en absoluto pacífico que derechos y normas sean lo mismo. Desde luego la tradición jurídica y política que da origen al constitucionalismo proclama "como evidentes estas verdades: que todos los hombres son creados iguales; que son dotados por su Creador de ciertos derechos inalienables"90, y que estos derechos son "naturales, imprescriptibles e inalienables"91. Es importante destacar que esta visión no forma parte del pasado, sino que desde luego goza de muy buena salud tanto desde el punto de vista doctrinario ${ }^{92}$ como del normativo ${ }^{93}$.

Por eso desde esta perspectiva el rol de las normas jurídicas no es el de crear aquellos derechos ${ }^{94}$, sino que de reconocerlos para protegerlos y, desde luego, eso supone que derechos y normas no son lo mismo. Y si bien desde el punto de vista lingüístico las normas que los reconocen pueden ser enunciados más bien genéricos y no acabados, ello es así precisamente porque no son los derechos mismos. Por esa razón es posible entender que "estas normas genéricas aun en 'estado bruto' colisionan entre sí, como ocurre cuando se habla en abstracto de libertad de expresión y derecho a la intimidad"95. Pero esto no significa que los derechos colisionen, o más bien dicho que los contenidos de ellos colisionen ${ }^{96}$.

\section{Los derechos colisionan y no tienen limites}

De lo dicho recién se desprende un segundo problema que presenta la posición de Alexy, a saber, que obliga a dar por sentado que los derechos colisionan y, por

\footnotetext{
${ }^{90}$ Declaración de independencia de los Estados Unidos de Norteamérica, de 4 de julio de 1776.

${ }^{91}$ Declaración francesa de los Derechos del Hombre y del Ciudadano de 1798.

${ }^{92}$ Por ejemplo, DwORKIN y sus Derechos en serio (1984) o el trascendental trabajo de FinNis Derecho natural $y$ derechos naturales (2000, en especial 227-259).

${ }^{93}$ A modo de ejemplo, el Preámbulo de la Convención Americana de Derechos Humanos señala, entre otras cosas, que existen "derechos esenciales del hombre", que "tienen como fundamento los atributos de la persona humana", y nuestra propia Constitución proclama como límite de la soberanía "el respeto a los derechos esenciales que emanan de la naturaleza humana".

${ }^{94}$ Esta visión iusnaturalista carecería de sentido si no reconociese que evidentemente el derecho positivo puede también crear otros derechos. Pero éstos no pueden ser considerados "inherentes" o "naturales", porque precisamente corresponden a una creación, y en tal carácter su contenido será el que determine quien lo creó, sea éste el constituyente o el legislador.

${ }^{95}$ Bertelsen (2010), 49.

${ }^{96}$ Ibid.
} 
ende, que los derechos no tienen límites. Sin embargo, en materia de conflictos o choques de derechos existen al menos otros dos criterios: el de jerarquización ${ }^{97} y$ el de determinación del contenido esencial ${ }^{18}$, y este último afirma que los derechos no colisionan, sino que tienen un contenido esencial que permite diferenciarlos de otros derechos, de otras instituciones jurídicas o de hechos ${ }^{99}$. Ello implica que los derechos tienen límites y que no son "ilimitados, pues tal cosa no sería natural ni posible, ni fue ésa la intención de los iniciadores del constitucionalismo, ni sería compatible con el sentido común" ${ }^{100}$. Por el contrario, los derechos están dotados de un contenido, y por ende de límites, y la labor de los operadores jurídicos es de delimitación, es decir, de descubrimiento y constatación de los límites ${ }^{101}$. A este respecto es interesante lo que nos dice Häberle, quien parte de la base de que efectivamente los derechos fundamentales tienen contenido y límites ${ }^{102}$, que deben deducirse en los casos concretos ${ }^{103} \mathrm{y}$, a su juicio, la ponderación es una herramienta para determinarlos ${ }^{104}$.

\footnotetext{
${ }^{97}$ Como acertadamente señala Bertelsen, debe destacarse que tanto este criterio como el de ponderación tienen en común el que son conflictivistas, pues los dos entienden "los derechos fundamentales como facultades ilimitadas, sin que ninguno de los derechos en pugna esté dispuesto a restringirse". Ibíd.

${ }^{98}$ Sobre los diversos métodos de solución de conflictos pueden de derechos consultarse, entre otros, SERNA (1994); De Otto (1998); Cianciardo (2000); Serna y Toller (2000); Bertelsen (2010).

${ }^{99}$ Como destaca Ignacio de Otto, "cualquier derecho o libertad, fundamental o no, ampara aquello que ampara y nada más". Esta afirmación queda muy bien ilustrada a través de algunas situaciones planteadas por el mismo autor. Así por ejemplo, en el caso "de la prohibición de utilizar explosivos para hacer una obra de arte o en la de instalar un laboratorio peligroso en una vivienda, nos hallamos ante normas que no regulan supuestos de hecho pertenecientes al derecho fundamental, sino de otra naturaleza, aunque puedan guardar una ocasional relación con el derecho propiamente dicho. La sanción de un eventual incendio neroniano no es limitación del arte, sino sanción de un incendio". Dе Отто (1998), 150 у 146.
}

${ }^{100}$ Pereira (2006), 257.

${ }^{101}$ Un enfoque distinto sobre límites, limitación, delimitación y regulación puede consultarse en ALDUNATE (2008), 242-252.

${ }^{102}$ En concreto, Häberle sostiene que "el contenido y los límites de los derechos fundamentales hay que determinarlos a partir de la totalidad del sistema jurídico-constitucional de valores al que está ordenado cualquier derecho fundamental". Pero Häberle va más allá, al sostener que ello es posible debido a que los derechos fundamentales tienen "límites inmanentes", lo que implica "que la concretización de los límites admisibles de los derechos fundamentales no es un proceso que afecte a los mismos desde fuera", puesto que este proceso debe hacerse respetando la esencia de ellos. Hä̈ERLE (2003), 52.

${ }^{103}$ Ibid., 36.

${ }^{104}$ Según Häberle, el significado de la ponderación está en estrecha relación con el orden objetivo y jerárquico de valores contemplado en la Constitución alemana: "Su significación jurídico-constitucional es evidente, si se tiene presente que el orden de valores es un orden jerárquico de valores y un orden de relación de valores". HÄBERLE, 33. 
$\mathrm{Al}$ respecto no puede dejarse de señalar que tratándose del Legislador y en su caso del Ejecutivo, su labor delimitadora sólo podrá tener lugar conforme a las previsiones que al respecto contenga la respectiva Constitución ${ }^{105}$. Distinta es la situación del juez, ya que éste deberá acometer esta tarea cada vez que se le someta un conflicto jurídico en que las pretensiones de las partes involucren derechos. En este último sentido la determinación del contenido esencial es también una cuestión de caso concreto ${ }^{106}$.

En definitiva, y como explica Aldunate, "aparece como mucho más congruente, desde un punto de vista dogmático, considerar el conflicto entre particulares que alegan derechos fundamentales, como lo que simplemente es: un conflicto entre el ejercicio de la libertad de un individuo y la libertad o derecho de otro, que debe ser resuelto a partir de los límites que entre uno y otro sea capaz de trazar el juez a partir del ordenamiento jurídico vigente, sin sustituirlo por una operación de ponderación entre derechos o, al menos, no como ponderación a nivel de derechos fundamentales" 107 .

3. El trasfondo consecuencialista: Un derecho debe ser "sacrificado" en favor de otro

Un tercer problema radica en que hacer "pesar" un derecho más que otro en el caso concreto, conlleva restarle valor, o como señala Bertelsen, en la práctica supone "la derogación del respectivo derecho"108. En términos aún más duros, Aldunate sostiene que la ponderación de derechos "enturbia" la solución de los conflictos entre particulares, porque "la ponderación siempre tiene que llegar a una consecuencia difícilmente sustentable, a saber: que respecto de su protección, en un caso, un derecho fundamental es, por así decirlo, más fundamental que otro" ${ }^{109}$. Desde luego ello resultará descorazonador para la parte en contra de la cual se hizo valer en un pleito el mayor "peso" del derecho de su contraparte, porque conlleva el "sacrificio" de su derecho. Pero además revela que el consecuencialismo está en la base de este tipo de razonamiento, pues la consecución de un bien se hace a costa de otro bien, y se olvida que "una acción que por sí misma atenta contra algo intrínsecamente valioso es imposible que sea buena" ${ }^{110}$.

\footnotetext{
${ }^{105}$ Como se sabe, en el caso de Chile esa función sólo puede ser cumplida por el legislador, cuando la Constitución expresamente lo haya contemplado y autorizado (art. 19 № 26).

${ }^{106}$ Acerca de la vinculación de los poderes públicos a los derechos fundamentales en Chile, ver ALDUNATE (2008), 183-210.

${ }^{107}$ Aldunate (2008), 279.

${ }^{108}$ BeRTELSEN (2010), 50.

${ }^{109}$ Aldunate (2008), 278-279.

${ }^{110} \operatorname{IsLER}(2011), 43$.
} 
En palabras de Finnis, uno de los problemas del consecuencialismo es que quienes lo practican "centran su atención en algo en lo que ya han puesto sus corazones (un aumento de la riqueza nacional mediante la colectivización de la agricultura, poner fin a la guerra, detectar a los herejes y criminales, ser reelegido Presidente, poner fin al dolor de esa joven mujer...). Se enfatizan 'las' buenas consecuencias de esto, y 'las' malas consecuencias de omitirlo o de no lograr conseguirlo. Se quita importancia a exigencias tales como la imparcialidad interpersonal para juzgar, la fidelidad de los compromisos, etc. De este modo, se fuerza el 'cálculo' para que proporcione una solución determinada...."111. Como se comprenderá, esto no parece ser muy acorde a la seguridad jurídica y a la previsibilidad de los actos de los poderes públicos y, en último término, pareciera que tampoco es muy coincidente con la justicia, que es el fin propio del Derecho ${ }^{112}$.

\section{El parámetro en base al cual se deben "pesar" los derechos}

Un cuarto problema consiste en que hay un riesgo evidente de que la determinación de cuál derecho "pesa" más, sirva para encubrir las preferencias ideológicas o valóricas del juzgador y que, por ende, el conflicto se resuelva en base a estas últimas y no en consideración a un parámetro objetivo. Evidentemente se puede pensar que el problema se resuelve mediante la determinación de parámetros objetivos, lo que usualmente lleva a la utilización de expresiones como el "consenso social, la eficiencia económica o a conceptos jurídicos indeterminados de connotación variable según el momento, como pueden ser los de 'relevancia pública de la información', 'interés general', 'medio de difusión social"” 113 .

Pero esa es sólo una solución en apariencia. Y es que dichas expresiones y conceptos pueden ser precisamente un medio que permita hacer aún más fácil la introducción de concepciones subjetivas y apreciaciones personales, disfrazadas de aparente objetividad, de la manera que señala Finnis en su crítica al consecuencialismo mencionada precedentemente ${ }^{114}$.

\footnotetext{
${ }^{111}$ FINNIS (2000), 147.

${ }^{112}$ No obstante, hay que precisar que, como señala Isler, Alexy no parece ser un consecuencialista. Sin embargo, la doctrina que ha desarrollado sus planteamientos sí lo es. Al respecto ver IsLER (2011), 47-52.

${ }^{113}$ BERTELSEN (2010), 50. Sobre la necesidad de que la interpretación constitucional se haga sobre la base de parámetros objetivos ver ARAGÓN (1999), 93-101.

${ }^{114} \mathrm{Al}$ respecto Aldunate concluye que la ponderación de derechos "lleva siempre irremediablemente a una valoración moral, pero no de derecho, de los elementos que llevan a preferir un derecho respecto de otro". Aldunate (2008), 279.
} 


\section{B. Proporcionalidad y exceso de poder}

A estas alturas se comprenderá que a pesar de la amplia difusión de las tesis de Alexy, lo cierto es que la proporcionalidad no puede identificarse necesariamente como un mecanismo destinado a resolver conflictos o colisiones de derechos. En esencia, el principio de proporcionalidad fue concebido más bien como un mecanismo destinado a controlar el ejercicio de potestades públicas a la hora de regular el ejercicio de derechos. En palabras de Aldunate, el fundamento "del principio de proporcionalidad se deriva de estar los poderes públicos vinculados a los derechos fundamentales y, en consecuencia, no ser admisible para ellos una disminución de las posibilidades de actuación de los titulares de derechos fundamentales si no es en virtud de una causa justificada, y solamente en la medida necesaria para obtener el fin que justifica dicha causa" 115 .

Conviene por tanto reiterar que, como se señaló al comienzo de este trabajo, el principio de proporcionalidad "fue acunado como un criterio de control sobre los poderes discrecionales de la administración y como límite al ejercicio del poder de policía"116. Fue sobre esa base que el TCF alemán "llevó la máxima de la proporcionalidad al control de los actos estatales que regulan o intervienen sobre los derechos fundamentales"117. En tal sentido, y como sostiene Fernández, el "término jurídico 'proporcionalidad', en última instancia, combina elementos característicos de la justicia del caso concreto -mide el impacto que sobre los ciudadanos tiene la intervención estatal-; de la lógica de la moderación en el ejercicio del poder; con la carga o el deber de motivar que al Estado incumbe"118.

Por tanto, la proporcionalidad es antes que todo un mecanismo de control del poder o, lo que es lo mismo, es un instrumento destinado a medir si la intervención estatal es o no lícita. Y no lo será, si en la práctica ella se traduce en la anulación o derogación del derecho o libertad de que se trate.

\section{EL PRINCIPIO DE PROPORCIONALIDAD EN EL SISTEMA} CONSTITUCIONAL CHILENO

\section{A) La proporcionalidad como principio implícito en la Constitución chilena}

La Constitución chilena no contiene ninguna norma que consagre expresamente el principio de proporcionalidad, aunque puede entenderse "implícito en las reglas

\footnotetext{
${ }^{115}$ Ibid., 264.

${ }^{116}$ SAPAG (2008), 170-171.

${ }^{117}$ Ibid., 171.

${ }^{118}$ FERNÁNDEZ (2008), 277.
} 
del Estado de Derecho, siendo un principio inherente a éste"119. Más aún, y como acertadamente señala Nogueira, "el principio de proporcionalidad se encuentra subsumido en el ordenamiento constitucional chileno en la garantía genérica de los derechos establecida constitucionalmente en las bases de la Institucionalidad que dan forma al Estado de Derecho (artículos $6^{\circ}$ y $7^{\circ}$ ), en el principio de prohibición de conductas arbitrarias (art. 19 No 2) y en la garantía normativa del contenido esencial de los derechos (art. 19 No 26 de la Constitución), además del valor justicia inherente al Derecho" ${ }^{120}$. Asimismo, puede entenderse también implícito en el art. 19 No 3, a propósito del derecho al debido proceso $^{121}$, y en el art. 19 o 20 , al reconocer el derecho a la igual repartición de los tributos, y prohíbe al legislador "establecer tributos manifiestamente desproporcionados o injustos" (inciso $\left.2^{\circ}\right)^{122}$.

\section{B) La proporcionalidad como criterio de control en la jurisprudencia del Tribunal Constitucional de Chile (TC)}

\section{El test de proporcionalidad en la jurisprudencia del TC}

En general, en los casos de que ha conocido el TC aplicando este principio ${ }^{123}$, se verifica que ha utilizado el test de proporcionalidad, aunque no necesariamente en sus cuatro pasos. Y así, por ejemplo, en algunas sentencias el TC sólo chequea si existe relación ente los medios legítimos utilizados y el fin perseguido. En tal sentido el TC ha señalado que la regulación legal de los derechos "debe ser razonable, no arbitraria, sirviendo como referencia del juicio de razonabilidad la concurrencia del principio de proporcionalidad, determinado por la relación coherente entre los medios utilizados y los fines legítimos perseguidos" ${ }^{124}$.

\footnotetext{
${ }^{119}$ Nogueira (2008), 246.

${ }^{120}$ Nogueira (2010), 374. En este mismo sentido ver Nogueira (2009), 120-121.

${ }^{121}$ Sobre la proporcionalidad y el debido proceso sustantivo, a propósito del exceso de poder en las actuaciones de la Administración, ver por ejemplo Alarcón (2000), 29-30. También Carrasco (2008), 193-205. Sobre la proporcionalidad como principio general del Derecho Administrativo, en particular de la potestad sancionadora de la Administración, ver BERMúdez (2010), 190-192.

122 Sobre el principio de proporcionalidad en materia tributaria ver EvANs (1998), 163-167; FERNÁNDEZ (2000), 357-371.

${ }^{123}$ Por ejemplo sentencias roles 541-06, de 13 de julio de 2006; 790-07, de 25 de mayo de 2007; 1046-08, de 3 de marzo de 2008; 1061-08, de 17 de abril de 2008, 1138-08, de 26 de mayo de 2008; 1140-08, de 2 de junio de 2008; 1182-08, de 22 de julio de 2008; 1193-08, de 1 de agosto de 2008; 1201-08, de 13 de agosto de 2008; 1204-08, de 20 de agosto de 2008; 1253-08, de 13 de octubre de 2008; 1254-08, de 15 de octubre de 2008; 1260-08, de 22 de octubre de 2008; 1262-08, de 23 de octubre de 2008; 1279-08, de 28 de noviembre de 2008; 1345-09, de 10 de marzo de 2009; 1463-09, de 18 de agosto de 2009; 1812-10, de 1 de septiembre de 2010, y 1816-10, de 1 de septiembre de 2010.

${ }^{124}$ Sentencia Rol No 541-06, de 13 de julio de 2006, considerando 15.
} 
En otras sentencias el TC ha utilizado el test completo, aunque de manera no del todo clara. A modo de ejemplo en la sentencia Rol No 1.046-08, de 3 de marzo de 2008, sostuvo que en el examen de constitucionalidad de normas legales "debe necesariamente revisarse si las limitaciones que ellas establecen se encuentran suficientemente determinadas por la ley y si están razonablemente justificadas; esto es, si persiguen un fin lícito, resultan idóneas para alcanzarlo y si la restricción que imponen puede estimarse proporcional al logro de esos fines lícitos que la justifican" (considerando 22) ${ }^{125}$. Y en la sentencia Rol No 1.06108, de 17 de abril de 2008, dijo que "si bien el legislador goza de discreción y de un amplio margen en la regulación de las relaciones sociales, debe cuidar que las restricciones al goce de los derechos que puedan resultar de tales regulaciones encuentren justificación en el logro de fines constitucionalmente legítimos, resulten razonablemente adecuadas o idóneas para alcanzar tales fines legítimos y sean -las mismas restricciones- proporcionales a los bienes que de ellas cabe esperar, resultando, por ende, tolerables a quienes las padezcan en razón de objetivos superiores $\mathrm{o}$, al menos, equivalentes"( considerando 17$)^{126}$.

Más recientemente, el Tribunal ha dado paso a una aplicación más clara y abierta del test de proporcionalidad al señalar que "los límites al derecho consagrado en la Constitución deben, como ha señalado reiteradamente este Tribunal, pasar un examen de proporcionalidad; esto es, perseguir fines lícitos, constituir la limitación un medio idóneo o apto para alcanzar tal fin y resultar el menoscabo o limitación al ejercicio del derecho, proporcional al beneficio que se obtiene en el logro del fin lícito que se persigue" 127.

A su vez en la sentencia Rol No 1.463-09, de 18 de agosto de 2009, a propósito del análisis de constitucionalidad del artículo 2331 del Código Civil, dijo que si bien "no le corresponde evaluar el mérito de las decisiones legislativas, la restricción de derechos debe satisfacer un mínimo test de proporcionalidad, sobre todo cuando ello importa establecer un tratamiento diferenciado. Para examinar la procedencia constitucional de las distinciones establecidas por el artículo 2331 del Código Civil, es necesario, en primer lugar, analizar que la restricción del derecho a la honra persiga un fin legítimo; en segundo lugar, determinar que la

\footnotetext{
${ }^{125}$ Sentencia del Tribunal Constitucional, Rol No 1.046-08 de 3 de marzo de 2008, considerando 220.

${ }^{126}$ En sentido similar ver sentencias roles Nos. 1.182-08, de 22 de julio de 2008; 1.193-08, de 1 de agosto de 2008; 1.201-08, de 13 de agosto de 2008 (en todas el considerando 21); 1.253-08, de 13 de octubre de 2008 , considerando $16 ; 1.262-08$, de 23 de octubre de 2008, considerando $23 ; 1.279-08$, de 28 de noviembre de 2008, considerando 18; 1.345-09, de 10 de marzo de 2009, considerando 10 .

${ }^{127}$ Considerando 21 de las sentencias roles $\mathrm{No}^{\circ}$. 1.182-08, de 22 de julio de 2008, 1.193-08, de 1 de agosto de 2008 y 1.201-08, de 13 de agosto de 2008.
} 
norma resulta adecuada e idónea para alcanzar dicho fin y, por último, clarificar si la diferencia es razonable en relación con el valor del fin propuesto" ${ }^{\prime 28}$.

2. El principio de proporcionalidad como mecanismo de protección de derechos y de control del exceso de poder en la jurisprudencia del TC

Como ya dijo, el principio de proporcionalidad se vincula a ciertos derechos constitucionales, y la jurisprudencia de nuestro TC demuestra que lo utiliza usualmente como criterio destinado a la protección de aquéllos mediante el control del exceso de poder. En palabras del propio TC "si bien a la justicia constitucional le está vedado calificar el mérito de la decisión legislativa, el examen de constitucionalidad que le incumbe le exige determinar la existencia de reglas suficientemente precisas y específicas en el precepto que limita el respectivo derecho constitucional, para evitar excesiva discrecionalidad en su aplicación" ${ }^{129}$.

En concreto, la jurisprudencia del TC revela la utilización del principio de proporcionalidad como un criterio para determinar si una diferenciación es lícita o no lo es, si se han observado o no los requisitos propios de todo debido proceso, o si los preceptos legales que regulan, complementan o limitan derechos respetan el contenido esencial de éstos.

a) El principio de proporcionalidad como criterio de control de la diferenciación

Como se dijo recién, el principio de proporcionalidad ha sido utilizado por el TC para determinar si determinadas diferenciaciones adoptadas por el legislador son o no constitucionales. Es interesante considerar que, según se demostró en el trabajo "El Principio de Razonabilidad en la Jurisprudencia del Tribunal Constitucional" (Estudios Constitucionales año 9, № 1-2011-, 199-226), el TC ha usado en varias oportunidades el principio de razonabilidad para analizar la licitud constitucional de las diferencias que puedan fijar las leyes. Desde este punto de vista, en análisis de las sentencias del TC demuestra que la aplicación del principio de proporcionalidad es menor y que, en general, lo ha hecho como una forma de determinar si hay o no arbitrariedad o falta de razonabilidad en la diferenciación. Sobre esta base pueden extraerse los criterios que se señalan a continuación.

i. La institución del abogado de turno gratuito infringe la igualdad ante las cargas públicas por ser contraria al principio de proporcionalidad. En la sentencia Rol No 1.254 el TC debió pronunciarse sobre el requerimiento de inconstitucionalidad del artículo 595 del Código Orgánico de Tribunales (COT), relativo al sistema de abogado de turno. Entre las normas constitucionales que podrían estar vulneradas por dicha norma están los numerales 2 y 20 del art. 19, es decir, el

${ }^{128}$ Sentencia Rol No 1.463-09, de 18 de agosto de 2009, considerando 22.

${ }^{129}$ Sentencia Rol No 541-06, de 13 de julio de 2006, considerando 15. 
principio de igualdad ante la ley y la igualdad ante las cargas públicas. Al respecto el TC sostuvo que un primer análisis del precepto cuestionado "podría suponer que no contravendría la Carta Fundamental, desde el momento en que quienes se encuentran en la misma situación serían todos los abogados a quienes se les puede imponer -eventualmente y bajo ciertos supuestos- dicha carga personal. No obstante, y por el contrario, un estudio comparativo con las demás profesiones liberales haría merecedora de reproche a la norma, habida cuenta de que el turno gratuito sólo se exige respecto de los abogados y no así en relación a otras profesiones que cumplen una función social como la medicina, arquitectura o pedagogía, vinculadas a bienes jurídicos tan o más relevantes como son la vida, la salud, la vivienda y la educación, respectivamente"130.

No obstante, el TC efectuó igualmente un examen de proporcionalidad del referido artículo 595 del COT. Para ello procedió a analizar si el objetivo de la norma era o no legítimo, si el medio utilizado era idóneo y si el grado de intervención de la medida era idóneo para conseguir el objetivo. Al respecto el TC en primer lugar que "la imposición de la obligación de defender a determinadas personas de escasos recursos constituye un fin razonable"131. Más aún, el TC señaló que el legislador puede excepcional y supletoriamente obligar a los abogados a dar asistencia jurídica, a fin de "cumplir con el mandato constitucional de dar asistencia legal a quienes no puedan procurársela por sí mismo". Pero a continuación agregó que "ello no autoriza la circunstancia de que no se remunere dicha labor profesional. Así, tal carga de gratuidad no aparece como un medio necesario ni se justifica para alcanzar el fin constitucional perseguido" (considerando 11) ${ }^{132}$.

En base a esas consideraciones, el TC declaró inconstitucional el artículo 595 del COT.

ii. La rebaja del monto de las pensiones de jubilación adoptada con el fin de moderar el gasto fiscal no infringe la igualdad ante la ley por ser acorde al principio de proporcionalidad. En la sentencia Rol No 790-07133, el TC debió pronunciarse sobre la inaplicabilidad de los artículos $4^{\circ}$ y 29 de las Leyes $\mathrm{No}^{\circ} .18 .549$ y 18.669 , que rebajaron las pensiones de una parte de los jubilados que percibían pensiones superiores a determinado monto. El TC efectuó el correspondiente análisis de

\footnotetext{
${ }^{130}$ Sentencia Rol No 1.254-08, de 15 de octubre de 2008, considerando 47.

${ }^{131}$ Ibid., considerando 61. El mismo criterio ha sido reproducido en las sentencias roles 755-07, 22 de marzo 2007; 1.138-08, de 26 de mayo de 2008 y 1.140-08, de 2 de junio de 2008, considerandos 41, 38, 32 , respectivamente.

${ }^{132}$ El mismo criterio ha sido reproducido en las sentencias roles 755-07, 22 de marzo 2007; 1.138-08, de 26 de mayo de 2008 y $1.140-08$, de 2 de junio de 2008, considerandos 41, 38, 32, respectivamente.

${ }^{133}$ De 25 de mayo de 2007.
} 
proporcionalidad de la medida, en concreto, si el fin perseguido era legítimo, y si la diferencia establecida resultaba idónea o adecuada al logro del fin perseguido.

El TC consideró que la moderación del gasto fiscal y la mejora de las pensiones más bajas de las personas de mayor edad eran objetivos legítimos y que, por ende, "establecer un sistema de reajuste que diferencie sobre la base de criterios de edad y monto de las pensiones, estableciendo escalas decrecientes de reajuste según aumente el monto de las pensiones a reajustar y disminuya la edad del pensionado. Ambos criterios se avienen con la finalidad de moderar el gasto público y con criterios de justicia distributiva" (considerando 26). En virtud de lo anterior, resolvió "que la distinción legislativa se encuentra dentro del abanico de tratamientos que pueden considerarse proporcionados, habida cuenta de la situación de hecho en que se encontraban las finanzas públicas del país a esa fecha, la finalidad de la ley que ya ha sido analizada y, particularmente, el hecho de que los bienes y derechos afectados por ella, que se traducen en el reajuste futuro de las pensiones, no pueden, en conformidad al derecho chileno, y según se razonará más adelante, ser considerados como propiedad o derechos adquiridos del pensionado, sino como meras expectativas" (considerando 27).

iii. La imposición de una pena mayor en consideración al resultado del delito no constituye una discriminación arbitraria, por ser acorde al principio de proporcionalidad. En la sentencia Rol No 1.584-09, de 31 de diciembre de 2009, el TC analizó un requerimiento de inaplicabilidad de los artículos 317 inciso $1^{\circ}$ con relación al artículo 315 inciso $2^{\circ}$ del Código Penal. En concreto, debió pronunciarse sobre la posible inaplicabilidad de las agravantes contempladas en el primero de esos preceptos, por infringir el artículo 19 No 2 de la Constitución, por establecer una diferencia arbitraria. A diferencia de los casos anteriores, en éste, el TC no aplicó completamente el test de proporcionalidad, y se limitó a declarar que a su juicio "existe una adecuada correlación entre la pena agravada del artículo 317, inciso primero, del Código Penal y la valoración social del hecho incriminado. El principio de que a mayor gravedad en la conducta, superior es la pena, se ve satisfecho tratándose de la muerte o grave enfermedad generada por un comportamiento ilícito. La producción del resultado no debe necesariamente excluirse como elemento de la penalidad. Así, el ejemplo clásico de la estimación de la pena en el delito frustrado versus el consumado, asume precisamente que la misma subjetividad sea el antecedente de distintas penas según el resultado verificado" (considerando 22).

b) El principio de proporcionalidad como criterio de control del respeto al debido procedimiento jurídico a propósito del principio solve et repete

En el mencionado trabajo "El Principio de Razonabilidad en la Jurisprudencia del Tribunal Constitucional", se comprobó que el TC ha usado profusamente el principio de razonabilidad para analizar medidas legales que pudieran afectar 
el derecho al debido procedimiento jurídico. Sin embargo, y al igual que como ocurrió con la aplicación del principio de proporcionalidad a propósito de la igualdad, el TC no ha aplicado de la misma forma el principio de proporcionalidad como criterio de control del respeto al debido proceso. De hecho nuestro análisis demuestra que la proporcionalidad ha sido aplicada específicamente a propósito del enjuiciamiento de la regla solve et repete.

i. No es acorde al principio de proporcionalidad el solve et repete del artículo 171 del Código Sanitario. En la sentencia Rol No 1.345-09, de 10 de marzo de 2009, el TC conoció de oficio de la posible inconstitucionalidad del artículo 171 del Código Sanitario ${ }^{134}$, que consagraba el solve et repete para reclamar de multas cursadas por el Servicio Nacional de Salud. El TC procedió a revisar si los fines perseguidos con esta medida eran legítimos, si la medida era adecuada o idónea para cumplir tales objetivos, y si la carga que imponía era proporcional a los fines perseguidos y, por tanto, tolerables para quienes se les imponía en razón de objetivos superiores o equivalentes.

El TC consideró que desincentivar reclamos injustificados o litigación puramente dilatoria era un objetivo constitucionalmente lícito, pero señaló que el medio no era idóneo por tres razones. En primer lugar porque la reclamación judicial no suspendía lo resuelto por la autoridad. En segundo lugar porque un sancionado con capacidad de pago podría igualmente litigar y, en tercer lugar, porque había otros medios idóneos para conseguir el mismo objetivo, sí cuenta con una serie de instrumentos destinados a desincentivar la litigación infundada o puramente dilatoria, y que son idóneos para tales objetivos, como por ejemplo "los exámenes de admisibilidad y la condenación en costas" (considerando 13).

El TC consideró entonces que el solve et repete "afecta y limita severamente el derecho del particular de acceder a la justicia para reclamar en ese foro de las sanciones administrativas de que ha sido objeto, del momento que, para hacerlo y como condición necesaria, debe consignar la totalidad de la multa que se le ha impuesto y de la que reclama" (considerando 16). Por último, al efectuar el test de proporcionalidad en sentido estricto, recordó que "el legislador, dentro de su ámbito de autonomía para legislar, debe elegir aquellas opciones que impliquen una limitación menor de los derechos, estándole prohibido afectar su contenido más allá de lo razonable, con relación a los objetivos que se quiere lograr”, y que para regular el ejercicio de un derecho el legislador debe hacerlo en forma prudente y

${ }^{134}$ Previamente el TC ya había declarado inaplicable este precepto en varias oportunidades. Por ejemplo sentencias roles 792-07, 30 de mayo de 2007; 1.061-08, de 17 de abril de 2008; 1.046-08, de 3 de marzo de 2008; 1.253-08, de 13 de octubre de 2008; 1.262-08, de 23 de octubre de 2008, y 1.279-08, de 28 de noviembre de 2008 . 
razonable (considerando 17). Todo ello le llevó a declarar la inconstitucionalidad del artículo 171 del Código Sanitario.

ii. El principio de proporcionalidad y la dudosa situación del solve et repete del artículo 30 inciso $2^{\circ}$ del Decreto Ley No 3.538

A pesar de la claridad de los planteamientos anteriores, en la sentencia Rol No 546-06, de 21 de julio de 2006, el TC no acogió una cuestión de inaplicabilidad respecto del artículo 30 inciso $2^{\circ}$ del Decreto Ley No 3.538. Aun cuando hubo empate de votos, el voto dirimente de su presidente determinó el rechazo de la declaración de inconstitucionalidad. La norma cuya aplicación se impugnó dispone que el afectado por las multas que puede imponer la Superintendencia de Valores y Seguros podrá reclamar de ellas o de su monto ante el juez de letras en lo civil que corresponda, previa consignación del $25 \%$ del monto total de la multa en la Tesorería General de la República. A juicio del requirente dicho precepto vulneraba su derecho al debido proceso a la igual protección de la ley en el ejercicio de sus derechos (artículo 19 No 3) de la Constitución, porque le imponía condiciones y exigencias pecuniarias de una cuantía que hace muy difícil acceder a la justicia. Asimismo, argumentó que se veía vulnerado el principio de igualdad ante la ley (artículo 19 No 2) y el derecho de petición (artículo 19 No 14), al establecer diferencias arbitrarias y al impedir que una persona pueda acceder a la justicia lo ejerza, al exigirle un requisito pecuniario que va más allá de los términos respetuosos y convenientes de los que habla la Constitución.

Los ministros Juan Colombo Campbell, Mario Fernández Baeza, Marcelo Venegas Palacios, Enrique Navarro Beltrán y Francisco Fernández Fredes, entendieron esta vez que la aplicación de la norma en cuestión no era contraria al derecho de acceso a la justicia. Para arribar a tal conclusión centraron su atención en la proporcionalidad en sentido estricto. Ello les llevó a concluir que la exigencia de consignación "no puede calificarse como una limitación irracional o arbitraria al ejercicio del derecho del requirente a recurrir ante la justicia ordinaria para que revise el acto impugnado, toda vez que el mismo tiene una justificación clara en el propósito de evitar que la determinación sancionatoria de la Superintendencia de Valores y Seguros sea dilatada sistemáticamente en su ejecución por el expediente de recurrirla ante el tribunal competente, aun sin basamento plausible. Por lo demás, en el caso de prosperar la reclamación del afectado ante el órgano jurisdiccional, el monto de lo consignado se le restituirá con la correspondiente actualización monetaria" (considerando 13). Por tal razón concluyeron que "el precepto impugnado no ha impedido al requirente el libre ejercicio de su derecho a reclamar ante el juez competente de la multa, ni le ha impuesto condiciones que le resultaran intolerables, arbitrarias, imprudentes o irrazonables" (considerando 13). 
Sin embargo, los ministros José Luis Cea Egaña, Raúl Bertelsen Repetto, Hernán Vodanovic Schnake y Jorge Correa Sutil y Marisol Peña Torres, sostuvieron lo contrario. Para alcanzar esta conclusión aplicaron el test de proporcionalidad. $\mathrm{Al}$ analizar si el objetivo de la medida era lícito, concluyeron en primer lugar que la obligación de consignar se aplica "indiscriminadamente a sujetos infractores y a quienes no serán considerados como tales. Se obliga así a consignar a quien ha querido ejercer su derecho a reclamar, en condiciones que no puede considerársele como infractor por una decisión que se encuentra reclamada y que no puede aún tenerse como definitiva" (considerando 14). Más aún, "si bien puede resultar lícito que los órganos fiscalizadores puedan, previo al proceso judicial y en sede administrativa, determinar la existencia de una infracción y la cuantía de una multa, la sanción no puede estimarse como cierta y definitiva para el ordenamiento jurídico sino una vez que no haya sido reclamada o, habiéndolo sido, una vez que tal reclamo haya sido resuelto en sede jurisdiccional e independiente. Así lo consagra nuestro sistema al permitir que se reclame de las respectivas decisiones administrativas en sede jurisdiccional, cuestión que no sólo está consagrada en la especie a nivel legal, sino también, con mayor jerarquía, en la propia Constitución Política (artículo 38 inciso segundo)" (considerando 15).

Por tal razón "el argumento de someter al sujeto fiscalizado al imperio del derecho no resulta convincente para justificar constitucionalmente la exigencia de consignar una suma significativa como la de la especie, toda vez que a través de ella se limita a priori y de manera significativa su derecho de acceso a la justicia, en condiciones que esta podría determinar que no es un infractor y que no merece reproche alguno" (considerando 17).

Con relación al objetivo de evitar reclamos meramente dilatorios, recordaron que no se acreditó que en los hechos se cumple efectivamente este fin, y que la medida "restringe igualmente el derecho fundamental de acceso a la justicia de quienes tengan fundamentos para reclamar de la sanción impuesta en sede administrativa, lo que podría ser el caso de autos" (considerando 18). Además, consideraron que "aun cuando el requirente calculara improbable ganar su reclamo ante la justicia, la disyuntiva ante la cual lo sitúa la norma en examen, consiste en pagar de inmediato el total fijado por la Superintendencia, sin reclamar de la multa, o pagar parte de la multa de inmediato $(25 \%)$ y diferir el resto. Tal cálculo de qué le conviene dependerá de factores financieros, del costo de litigar, de la posibilidad que el Tribunal le suba la multa, pero no se ve por qué la obligación de consignar previamente parte de la multa que el litigante estima que terminará pagando igual, podría motivarlo a no reclamar. No visualizamos de qué modo la consignación opera como un disuasivo al litigante temerario para convencerlo de no litigar, como sostiene la requerida" (considerando 19). 
Otro objetivo analizado por estos ministros fue el de dar más eficacia al actuar de la Administración. Si bien lo consideraron un fin lícito recordaron que "al escoger tales mecanismos, el legislador se encuentra limitado por el derecho de las personas que establece la Carta Fundamental, según lo obligan los artículos $1^{\circ}$ y $5^{\circ}$ de la Carta Fundamental y debe evitar que su actuar afecte, más allá de lo necesario, los derechos fundamentales o impida su libre ejercicio, (artículo 19 № 26), como puede llegar a ocurrir con la norma en examen, en que el legislador lo somete a exigencias que pueden llegar a hacerlo irrealizable o entrabarlo más allá de lo razonable, conforme a las condiciones financieras del reclamante" (considerando 20)

Pero además tuvieron presente que aquellos objetivos podían asegurarse también a través de otros medios menos gravosos y más prudentes, como "la declaración de admisibilidad de las acciones judiciales y la condenación en costas de los reclamantes que lo hagan sin fundamento plausible", o el sistema del artículo 22 de la Ley No 18.287 (Procedimiento ante los Juzgados de Policía Local), que permite una determinada rebaja del monto de la multa impuesta si el infractor se conforma y la paga sin reclamar de ella en sede judicial", o también "medidas cautelares destinadas a asegurar el cumplimiento del fallo y que se hacen procedentes cuando se convence a un juez de su necesidad de acuerdo a las particulares circunstancias de un caso" (considerando 21).

Por último, consideraron que la obligación de consignar la suma equivalente a un $25 \%$ de la multa era además desproporcionada en sentido estricto. Ello porque al no tener "límite alguno a la cuantía que arroje tal porcentaje, ......., limita de manera severa el derecho de acceder a la justicia del requirente, sin que tan significativa limitación pueda considerarse razonable, pues no guarda proporción alguna con el logro de fines lícitos, como los alegados en esta causa y, por el contrario, se muestra inepta para alcanzar aquellos que se han dado para justificarla" (considerando 24).

c) El principio de proporcionalidad como criterio de control del respeto al contenido esencial de los derechos

Como dice Häberle, el contenido esencial se corresponde con la idea de límites inmanentes de los derechos ${ }^{135}$. Por tanto supone partir de la base de que los derechos tienen límites, todo lo cual permite identificarlos y diferenciarlos de otros derechos, de otras instituciones jurídicas, o simplemente de meras situaciones fácticas. En este ámbito hay que destacar que, a diferencia del principio de razonabilidad, el TC ha hecho constante aplicación del principio de proporcionalidad para determinar si las regulaciones, complementaciones o limitaciones de derechos adoptadas por el

135 Häberle (2003), 58. 
legislador, han respetado o no su contenido esencial. Probablemente ha influido en ello los claros términos del mandato del artículo 19 № 26 de la Constitución, norma que consagra la garantía del contenido esencial de los derechos como límite a la facultad normativa del legislador para regular, complementar o, en su caso, limitar los derechos, cuando así lo hubiese contemplado el constituyente.

Dicha garantía lleva implícito el principio de proporcionalidad, a través de lo que García denomina acertadamente "grado de afectación del derecho"136. Esta idea entronca claramente con uno de los supuestos esenciales de la proporcionalidad, a saber, que la regulación, complementación o limitación de un derecho no puede suponer su negación o anulación.

En palabras del TC, se afecta el contenido esencial de un derecho cuando el legislador "lo somete a exigencias que lo hacen irrealizable, lo entraban más de lo razonable o lo privan de tutela jurídica" (sentencia Rol No 43, considerando 21). Por eso el TC ha señalado en reiteradas oportunidades que el legislador, dentro de su ámbito de autonomía para legislar, debe elegir aquellas opciones que impliquen una limitación menor de los derechos. Asimismo, el Tribunal ha sostenido que si bien el legislador tiene autonomía para reglar el ejercicio de un derecho, debe hacerlo prudentemente y "dentro de latitudes razonables" (sentencia Rol No 280 98 , de 16 de septiembre de 1998 , considerando 28$)^{137}$. Todo ello demuestra que la proporcionalidad es un instrumento clave para el enjuiciamiento de la ley que regule, complemente o limite derechos.

i. Es acorde al principio de proporcionalidad la fijación de altas multas y del pago de indemnización compensatoria por no pago de peajes. En la sentencia Rol No 541-06, de 13 de julio de 2006, el TC conoció una inaplicabilidad por inconstitucionalidad del artículo 42 del DFL No 164, de 1991 (Ley de Concesiones), que fue requerida por la Corte de Apelaciones de Santiago (CAS). La norma disponía que el juez de la causa debía, además de ordenar el pago de la suma adeudada, imponer el pago de una indemnización compensatoria por un monto de cuarenta veces el valor de aquella suma, con más reajustes e intereses, o, en su defecto, a título también de indemnización compensatoria, el pago de dos unidades tributarias mensuales, debiendo siempre imponer el monto que fuere mayor de entre los dos señalados. La CAS consultó al TC sobre la posible infracción del derecho de propiedad, ya que la norma cuestionada podría afectar su contenido esencial, porque la indem-

\footnotetext{
${ }^{136}$ GARCÍA (2004), 171.

${ }^{137}$ Estos criterios han sido reiterados en las sentencias roles 1.046-08, de 3 de marzo de 2008, considerando 22; 1.061-08, de 17 de abril de 2008, considerando 17; 1.253-08, de 13 de octubre de 2008, considerando $16 ; 1.262-08$, de 23 de octubre de 2008 , considerando $23 ; 1.279-08$, de 28 de noviembre de 2008 , considerando 18, y 1.345-09, de 10 de marzo de 2009, considerando 10 .
} 
nización compensatoria podría de facto tener carácter expropiatorio, y porque no se consideraba la real existencia de perjuicios.

En la resolución del asunto, el TC aplicó el criterio de proporcionalidad, para lo cual revisó el objetivo de la norma, su licitud y adecuación al fin, así como la proporcionalidad en sentido estricto. El TC sostuvo, en primer lugar, que el precepto perseguía un fin lícito, que no era otro que "asegurar el adecuado funcionamiento del sistema concesionado de infraestructura". Sin esta medida no se justificaría el cobro judicial de las tarifas, debido al costo que ello demandaría para la concesionaria. Por ende, los altos montos involucrados en el cobro judicial representan "un elemento disuasivo de la generalización de conductas que pongan en riesgo el régimen de concesiones, afectando el interés colectivo que su eficaz desenvolvimiento procura" (considerando 16). Todo ello llevó al TC a declarar que la aplicación de la norma legal no resultaba contraria a la Constitución.

ii. No es acorde al principio de proporcionalidad el principio solve et repete. Como se vio antes, en la sentencia Rol No 1.345-09, de 10 de marzo de 2009, el TC declaró la inconstitucionalidad del artículo 171 del Código Sanitario, que consagraba el solve et repete para reclamar de multas cursadas por el Servicio Nacional de Salud. Para arribar a su conclusión el TC aplicó el test de proporcionalidad, y llegó a la conclusión que dicha norma era inconstitucional, porque si bien el objetivo era lícito (evitar reclamos injustificados o litigación dilatoria), el medio no era idóneo, y limitaba más allá de lo razonable el derecho de acceso a la justicia (considerando 13). En suma, el solve et repete afecta el contenido esencial del derecho de acceso a la justicia.

iii. Es acorde al principio de proporcionalidad limitar el ejercicio de un derecho previsional a un plazo de caducidad o prescripción. En la sentencia Rol No 1.26008, de 22 de octubre de 2008, el TC conoció de una inaplicabilidad respecto del inciso segundo del artículo $4^{\circ}$ de la Ley $N^{o} 19.260$, que establece un plazo de caducidad (dos años) para el cobro de las mensualidades correspondientes a prestaciones de seguridad social. La requirente sostuvo que la aplicación del precepto violaba su derecho de propiedad y su derecho a la seguridad social sobre una pensión de orfandad de la que era titular. Ello porque la aplicación de la ley le privaba de las mensualidades correspondientes al período que medió entre el momento del fallecimiento del causante y el día en que se impetró el beneficio y solicitó su pago. A su juicio aquello constituía una auténtica expropiación sin indemnización compensatoria, lo que obviamente afectaba el contenido esencial de ambos derechos.

El TC rechazó la argumentación de la recurrente basada en el derecho de propiedad, porque "a la fecha de entrada en vigencia de la Ley No 19.260 aún no fallecía la madre de la peticionaria, por lo que ella no era titular del derecho a 
exigir la señalada pensión. Su expectativa estaba sujeta a un hecho futuro e incierto - condición-aún pendiente. En consecuencia, a la fecha de entrada en vigencia de la Ley No 19.260 no podía sostenerse que la requirente tuviera en su patrimonio el derecho a la pensión" (considerando 18) ${ }^{138}$.

En lo que respecta al derecho a la seguridad social y de su contenido esencial, el TC efectuó un análisis del problema acudiendo a la proporcionalidad para enjuiciar la medida. Para ello comenzó por analizar si el objetivo era lícito. Al respecto señaló que "un plazo de caducidad para impetrar un beneficio previsional puede y debe ser entendido como una limitación en el ejercicio de ese derecho" (considerando $33)^{139}$. Sin embargo, consideró que "el plazo de caducidad o prescripción antes referido persigue el fin lícito de brindar certeza respecto de los créditos que puedan cobrarse en contra del Fisco" (considerando 36) ${ }^{140}$.

En un segundo paso, el TC analizó la idoneidad de la medida, y señaló que "la prescripción es un instrumento o medio idóneo para lograr esa certeza o seguridad jurídica, en cuanto es el mecanismo típico que emplea el derecho para estabilizar situaciones jurídicas, aunque ellas sean anómalas, por el solo hecho de mantenerse inalteradas por un lapso de tiempo" (considerando 38) ${ }^{141}$. Finalmente, analizó la proporcionalidad en sentido estricto, concluyendo si bien no "cualquier plazo que se determine para extinguir la existencia de cualquier crédito resulte razonable", sí lo es el que contempla la ley cuya aplicación se impugnaba (considerando 38) ${ }^{142}$.

Todo lo anterior llevó al TC a concluir que "el derecho a la seguridad social no ha sido privado de aquello que le es consustancial o que resulta irreconocible, por el hecho de que una ley sujete ese derecho a un plazo de caducidad de dos años, pasado el cual no impide su ejercicio, pero limita el período de pago de las pensiones respectivas. Por los mismos motivos ya anotados, tampoco puede

\footnotetext{
${ }^{138}$ El TC agregó que "sobre las meras expectativas de que se cumpla la condición legal para que se pueda hacer efectivo un derecho, no puede haber propiedad, de modo que una ley que introduce un plazo de caducidad o prescripción para la exigencia del derecho mientras la condición aún yace incumplida no vulnera la propiedad" (considerando 20). Asimismo, concluyó que "no puede sostenerse que el inciso segundo del artículo $4^{\circ}$ de la Ley No 19.260 haya privado a la requirente de su derecho a recibir pensión, ya que el plazo de caducidad que allí se establece no extingue el derecho a una pensión, el que, conforme a lo dispuesto en el inciso primero de la misma disposición, es imprescriptible, sino que lo que extingue es el derecho a cobrar determinadas mensualidades" (considerando 26).

${ }^{139}$ En este mismo sentido sentencias roles 1.182-08, de 22 de julio de 2008, considerando 20; 1.193-08, de 1 de agosto de 2008, considerando 20; 1.201-08, de 13 de agosto de 2008, considerando 20 .

${ }^{140}$ En este mismo sentido, los considerandos 23 de las mismas sentencias mencionadas en la nota anterior.

${ }^{141}$ En este mismo sentido, los considerandos 25 de las mismas sentencias mencionadas en la nota anterior.

${ }^{142}$ En este mismo sentido sentencias roles 1.182-08, de 22 de julio de 2008, considerando 25; 1.193-08, de 1 de agosto de 2008, considerando 25; 1.201-08, de 13 de agosto de 2008, considerando 25 .
} 
estimarse que las limitaciones al ejercicio de derechos contempladas en la norma impugnada entraben su ejercicio más allá de lo razonable. Por ello, esta causal de inaplicabilidad debe también ser desestimada" (considerando 43) ${ }^{143}$.

iv. No es acorde al principio de proporcionalidad la limitación establecida en el artículo 2331 del Código Civil para las indemnizaciones derivadas de imputaciones injuriosas contra el honor o el crédito de una persona. En la causa Rol No 1.463-09, de 18 de agosto de 2009, el TC conoció de una cuestión de inaplicabilidad respecto del artículo 2331 del Código Civil (CC). Las parte requirente sostuvo que la aplicación de la referida norma sería contraria a su derecho a la honra y a su derecho a la integridad psíquica, reconocidos en los numerales 4 y 1 del artículo 19 de la Constitución. A su juicio dicho efecto se produciría porque el artículo 2331 del CC contempla una limitación al ejercicio de esos derechos. Dicho límite es doble. Por una parte exige que para demandar indemnización por injurias o calumnias se debe haber producido un perjuicio avaluable en dinero. Por otra, excluye la indemnización del daño moral, lo que contravendría el principio de responsabilidad. Todo esto supondría en último término afectar aquellos derechos en su esencia.

El TC entró al fondo del asunto manifestando que enjuiciaría la aplicación del precepto mediante la aplicación del test de proporcionalidad. En concreto, señaló que "si bien a esta Magistratura no le corresponde evaluar el mérito de las decisiones legislativas, la restricción de derechos debe satisfacer un mínimo test de proporcionalidad, sobre todo cuando ello importa establecer un tratamiento diferenciado. Para examinar la procedencia constitucional de las distinciones establecidas por el artículo 2331 del Código Civil, es necesario, en primer lugar, analizar que la restricción del derecho a la honra persiga un fin legítimo; en segundo lugar, determinar que la norma resulta adecuada e idónea para alcanzar dicho fin, $y$, por último, clarificar si la diferencia es razonable en relación con el valor del fin propuesto" (considerando 22).

Respecto de si el objetivo de la norma es o no legítimo, el TC sostuvo que era necesario analizar "en primer lugar, cuáles fueron las consideraciones o propósitos que tuvo el legislador al establecerlo y cuáles podrían ser las justificaciones que hoy podría tener dicha norma en el contexto del ordenamiento jurídico actual" (considerando 27). En tal sentido el TC hace suyo el razonamiento de los ministros Bertelsen y Correa, quienes en su prevención en el fallo Rol No 943-07, de 12 de septiembre de 2007, sostuvieron que "la norma en cuestión, de tan antigua data que resulta difícil suponer cuál sea hoy su justificación, podría también intentar explicarse como un modo de evitar los excesos que podrían

${ }^{143}$ En este mismo sentido, los considerandos 39 de las mismas sentencias mencionadas en la nota anterior. 
producirse en la avaluación excesiva del daño moral, siempre difícil de apreciar monetariamente. Pero, si tal fuere el caso, no resulta posible entender la razón de un trato desigual para los actos injuriosos que causan daño moral respecto del resto de los injustos que pueden producir análogos efectos y respecto de los cuales no existe la prohibición de indemnización que sólo se establece para este caso" (considerando 28; el párrafo citado aparece en el considerando $6^{\circ}$ de la prevención). El TC agregó que el contexto histórico de la norma cuestionada puede explicar el por qué de la exclusión, ya que "el derecho a la honra y al honor no se reconocían en la Constitución de 1833, y a que, por otra parte, el daño moral no se estableció expresamente en el Código Civil francés, el cual fue modelo del Código Civil chileno" (considerando 30).

No obstante, el TC concluye que el fin de la norma es legítimo, conclusión a la que llega mediante la aplicación de otro principio constitucional, cual es el de deferencia. Al respecto el TC señaló que "en virtud del principio de deferencia al legislador, este Tribunal estima que puede considerarse como fin legítimo que el legislador haya tenido en cuenta, para establecer dicha norma en el Código Civil, la protección de la libertad de expresión, contemplando una excepción a la regla general de que todo daño causado por un acto ilícito debe ser indemnizado, según lo prescribe el artículo 2329 del Código Civil. Ello, en razón de que puede sostenerse que la libertad de expresión se puede ver favorecida al restringirse el deber de indemnizar el daño moral que en su ejercicio se ocasione cuando no se cometan delitos penalmente sancionados" (considerando 30).

Por eso, zanjada la duda sobre la licitud del fin de la norma, el TC analizó a continuación la idoneidad y proporcionalidad de la medida, para lo cual tuvo presente en primer lugar "el hecho de que la situación de las comunicaciones ha cambiado sustancialmente desde la época en que se dictó el Código Civil hasta nuestros días. Hemos pasado de una prensa escrita de circulación restringida al desarrollo posterior de la radiodifusión y de la televisión analógica y digital y, desde hace algunos años, a la expansión masiva de internet y a la interrelación de todos esos medios entre sí y la telefonía celular. Estos adelantos han provocado -como hemos visto- cambios legislativos importantes y otros que están en curso en el Congreso Nacional" (considerando 30).

En segundo lugar, el TC analizó si existían otros medios idóneos para cumplir con el objetivo de la norma, y concluyó que sí "es posible identificar distintos mecanismos que cumplen mejor tal propósito. Entre ellos, por ejemplo, el establecimiento de estándares probatorios o estándares de convicción judicial que impidan que la indemnización de meras imputaciones injuriosas termine minando la libertad de expresión" (considerando 32). Por eso, al analizar la proporcionalidad en sentido estricto afirmó que "al impedirse siempre la indemnización del 
daño moral por determinadas afectaciones al derecho a la honra, ocasionadas por imputaciones injuriosas, se establece una distinción claramente arbitraria”, ya que "el legislador no es libre para regular el alcance de los derechos fundamentales que la Constitución reconoce y asegura a todas las personas. Por el contrario, y como lo dispone el artículo 19 , No $26^{\circ}$, de la misma, debe respetar la esencia del derecho de que se trata como también evitar la imposición de condiciones, tributos o requisitos que impidan su libre ejercicio"(considerando 35).

Finalmente, el TC consideró que la aplicación del artículo 2331 del CC vulneraba el contenido esencial del derecho a la honra, porque "en el presente caso, la norma resulta desproporcionada, al impedir de modo absoluto y a priori la indemnización del daño moral cuando se estima lesionado el crédito u honra de una persona por imputaciones injuriosas, con lo cual se afectaría en su esencia un derecho amparado por la Constitución (artículo 19 o 4ㅇ), vulnerando así lo prescrito por el artículo 19 No 260 de la Carta Fundamental" (considerando 37).

Más tarde, en las sentencias roles 1.679-10, de 7 de abril de 2010; 1.741-10, de 3 de junio de 2010, y 1.798-10, de 12 de agosto de 2010, el TC nuevamente debió pronunciarse sobre la aplicación del mismo precepto. En estos casos el TC ahondó en nuevas consideraciones vinculadas a la proporcionalidad para enjuiciar la aplicación de la norma. Así, el TC afirmó que "al fijar las condiciones de procedencia de la indemnización en casos de afectación a la honra el legislador debe respetar la esencia de los derechos involucrados, de conformidad al artículo 19, No 26ㅇ de la Constitución" (considerandos 13, 11 y 11, respectivamente). Luego el TC llama la atención sobre el hecho de que la norma junto con impedir la indemnización del daño moral por afectaciones a la honra, "no considera ningún tipo de excepción ni atiende a casos en que pudiera estimarse procedente una indemnización parcial" (considerandos 14, 12 y 12, respectivamente).

3. La proporcionalidad como sinónimo de razonabilidad, o como una manera de determinar si hay o no arbitrariedad. En varios de los fallos analizados es posible constatar que en ocasiones el TC usa indistintamente los conceptos de razonabilidad y de proporcionalidad, como auténticos sinónimos ${ }^{144}$. Pero como indicamos al comienzo de este trabajo, si bien se trata de conceptos parecidos, que persiguen el mismo objetivo de evitar la arbitrariedad, estricta y formalmente no son lo mismo. Más bien existe una relación de género a especie entre ambos, porque la

${ }_{144}$ Por ejemplo, en las sentencias 1.170-08, de 9 de julio de 2008; 1.307-09, de 15 de enero de 2009; 1.361 09, de 13 de abril de 2009; 1.399-09, de 29 de mayo de 2009; 1.414-09, de 18 de junio de 2009; 1.448-09, de 27 de julio de 2009; 1.535-09, de 12 de noviembre de 2009; 1.683-10, de 13 de abril de 2010; 1.801-10, de 16 de agosto de 2010; 1.812-10, de 1 de septiembre de 2010; 1.816-10, de 1 de septiembre de 2010, y 1.817-10, de 1 de septiembre de 2010, y 1.988-11, de 24 de junio de 2011. 
idea de razonabilidad abarca la proporcionalidad, siendo ésta una consecuencia o manifestación de aquélla.

No obstante, el TC ha usado también el criterio de proporcionalidad como un medio de comprobación de la arbitrariedad en los casos en que ha debido pronunciarse sobre la posible infracción del principio de igualdad, o sea, los relacionados con el abogado de turno gratuito y los de solve et repete. Como se señaló a propósito del análisis de dichos casos, el TC acudió al test de proporcionalidad como una forma de determinar si las normas enjuiciadas resultaban razonables o arbitrarias.

4. El principio de proporcionalidad como criterio de solución de conflictos de derechos. El TC ha aplicado de manera muy aislada el principio de proporcionalidad como mecanismo de solución de supuestos conflictos de derechos. Como se recordará, quienes consideran que los derechos pueden entrar en conflicto proponen como soluciones el uso del criterio de jerarquía de éstos, o la ponderación entre los mismos. Tanto en las sentencias roles No 976-07, de 2 de octubre de 2007; $1.218-08$, de 27 de agosto de 2008; 1.273-08, de 24 de noviembre de 2008 y 1287-08, de 16 de diciembre de 2008, que declararon inaplicable el artículo 38 ter de la Ley No 18.933, como en la Rol No 1.710-10, de 27 de abril de 2010, que declaró la inconstitucionalidad de aquél precepto, el TC se pronunció sobre la constitucionalidad del artículo 38 ter de la Ley No 18.933.

$\mathrm{Al}$ enjuiciar la norma primero en su aplicación y más tarde en abstracto, el TC aplicó el test de proporcionalidad, sin mencionarlo expresamente, y asumió también tácitamente una tesis conflictivista entre la igualdad ante la ley, el derecho a la protección de la salud y el derecho a la seguridad social, con los derechos a desarrollar actividades económicas y el derecho de propiedad. Y decimos que lo hizo de manera tácita, porque en ninguna parte menciona a estos últimos. No obstante, la lectura de estos fallos deja en claro que el TC ponderó entre unos derechos y otros ${ }^{145}$, y lo hizo sobre la base de dos argumentos básicos, a saber, la Constitución como un conjunto de valores, principios y normas de carácter objetivo, y el efecto horizontal de los derechos.

En lo relativo al test de proporcionalidad, si bien no lo menciona expresamente, a lo largo de las sentencias se verifica la aplicación de cada uno de sus pasos. De hecho la conclusión del voto de mayoría no pone en discusión ni el medio regulatoria empleado (la ley), ni el objeto (regular los ajustes de precio de los contratos de salud), sino más bien la necesidad, y sobre todo la proporcionalidad en sentido estricto de la medida.

\footnotetext{
${ }^{145}$ En el considerando 93 de la sentencia Rol No 1.710-10, de 27 de abril de 2010, el voto de mayoría, citando a Alexy, sostuvo que el problema debía dilucidarse mediante el criterio de ponderación.
} 
Así, los votos de mayoría de aquellas sentencias parten de la base de que la Constitución es un sistema orgánico, coherente y armónico de valores, principios y normas, lo que excluiría toda interpretación que anule o prive de eficacia a alguno de sus preceptos. Ello los lleva a darle una nueva al principio de subsidiariedad, al señalar que "no sólo los órganos del Estado deben respetar y promover los derechos consustanciales a la dignidad de la persona humana, sino que esa obligación recae también en los particulares, aunque sea subsidiariamente, puesto que el Código Supremo asegura la intangibilidad de tales atributos en toda circunstancia, cualesquiera sean los sujetos que se hallen en la necesidad de infundir vigencia efectiva a lo proclamado en sus preceptos" (sentencias roles 976-07, de 2 de octubre de 2007, considerando $34^{\circ} ; 1.218-08$, de 27 de agosto de 2008, considerando $35^{\circ}$, y $1.287-08$, de 16 de diciembre de 2008 , considerando $35^{\circ}$, respectivamente).

En otros términos, el Tribunal entendió que en virtud del efecto horizontal de los derechos se deriva la obligación de los particulares de dar eficacia al derecho a la salud, en subsidio del Estado. Tal sería el caso de las Isapres, como consecuencia de la aplicación a su respecto del art. 19 No 9 (en lo relativo al derecho a elegir entre el sistema público o privado de salud) y 19 No 26 (sentencias roles 976-07, de 2 de octubre de 2007, considerandos $36^{\circ}, 37^{\circ}, 38^{\circ}$ y $42^{\circ} ; 1.218-08$, de 27 de agosto de 2008 , considerandos $37^{\circ}, 38^{\circ}, 39^{\circ}$ y $43^{\circ}$, y $1.287-08$, de 16 de diciembre de 2008 , considerandos $37^{\circ}, 38^{\circ}, 39^{\circ}$ y $43^{\circ}$, respectivamente).

En consonancia con lo anterior, la posición de mayoría del TC entendió que la aplicación de las tablas de factores efectuada por las Isapres para modificar el precio del contrato de salud, constituía una "discriminación infundada o distinción carente de justificación razonable y, en esa medida, arbitraria”. Ello porque, a su juicio, si bien la referida tabla encuentro fundamento en la ley, "se torna evidente que tal disposición lesiona la esencia de la igualdad entre las partes asegurada por el artículo 19, № 2, de la Constitución" (sentencia Rol No 976-07, de 2 de octubre de 2007, considerando 62).

La posición de mayoría del fallo Rol No 1.273-08, de 24 de noviembre de 2008, precisa que no es acorde a la Constitución el criterio del art. 38 ter de la Ley No 18.933, en cuanto permite fijar los precios de los contratos de salud en consideración de la edad y del sexo. Para tal efecto el Tribunal Constitucional hace suya una doctrina de su símil alemán, según la cual "es necesario distinguir conceptualmente entre 'igualdades esenciales' y 'desigualdades esenciales'. Así, estamos en presencia de una igualdad esencial cuando 'personas, grupos de personas o situaciones, sobre la base de un punto de partida (tertium comparationis), son comparables"' (considerando 60\%).

Por tal razón, se lesiona "la igualdad ante la ley cuando un grupo de destinatarios de la norma, comparados con otro grupo de destinatarios de la norma, 
son tratados de manera distinta, a pesar de que entre ambos grupos no media ninguna diferencia de tal entidad o importancia que pudiera justificar un tratamiento desigual. Para poder dimensionar tales situaciones, esta fórmula requiere expresamente una ponderación en el sentido de examen de proporcionalidad, especialmente respecto de una diferencia de trato de gran intensidad, para lo cual se requiere que aquélla persiga un fin legítimo, que esa búsqueda sea necesaria y que presente una razonable relación con el valor del fin propuesto" (sentencia Rol No 1.273-08, de 24 de noviembre de 2008, considerando 60; sentencia Rol No 1.710-10, de 27 de abril de 2010, considerando 100).

Finalmente, la posición de mayoría de los fallos tantas veces mencionados es coincidente también en este punto. Sostiene que aun cuando no se señalen expresamente en el art. 19 No 18 , forman parte integrante del derecho a la seguridad social, como "principios rectores", la universalidad (subjetiva y objetiva), la integridad o suficiencia, la solidaridad y la unidad (considerandos $26^{\circ}$ al $30^{\circ}$, Rol No 1.218-08, de 27 de agosto de 2008; 26 a 30, Rol No 1.287-08, de 16 de diciembre de $2008 ; 131^{\circ}$ al $133^{\circ}$ y $135^{\circ}$, Rol № $1.710-10$, de 27 de abril de 2010). Por tal razón, la existencia misma de reajustes periódicos del precio del plan de salud previsional sólo por el aumento de edad sería inconstitucional, por atentar contra el derecho a la seguridad social consagrado en el art. 19 No 18 de la Constitución, "precepto que obliga al Estado a asegurar el acceso de todos los habitantes al goce de prestaciones básicas uniformes y a supervigilar el adecuado ejercicio de ese derecho (considerandos 62 $2^{\circ}$, Rol No 1.218-08, de 27 de agosto de 2008; 67º, Rol No 1.287-08, de 16 de diciembre de 2008; 78º, Rol No 1.273-08, de 24 de noviembre de 2008). A juicio del Tribunal Constitucional esa uniformidad exigida por la Constitución "resulta vulnerada si el costo de las cotizaciones para la asegurada por el disfrute de unas mismas prestaciones, se ve acrecentado por el mero hecho de progresar en edad, lo que al mismo tiempo produce, como natural efecto, el menoscabo del ejercicio adecuado de su derecho a la seguridad social" (considerando 79º, Rol No 1.273-08, de 24 de noviembre de 2008).

En resumen, el TC hizo un "balancing test" entre igualdad ante la ley, derecho a la protección de la salud y derecho a la seguridad social con los derechos constitucionales que amparan la actividad de las Isapres, o sea, derecho a desarrollar actividades económicas y derecho de propiedad. Y como se vio, el TC llegó a la conclusión que la regulación legal de la facultad de ajustar los precios de los servicios que dichas instituciones ofrecen, amparadas obviamente en los derechos ya mencionados, era contraria a la Constitución. Ello porque en el contexto de los valores, principios y normas de la Constitución, "pesan" más la igualdad ante la ley, el derecho a la protección de la salud y el derecho a la seguridad social. 


\section{BiBLIOGRAFÍA}

Alarcón, Pablo Andrés (2000): Discrecionalidad Administrativa. Un estudio de la Jurisprudencia chilena, Santiago, LexisNexis.

Aldunate Lizana, Eduardo (2008): Derechos fundamentales, Santiago, LegalPublishing.

AleXY, Robert (2007): Teoría de los derechos fundamentales, Madrid, Centro de Estudios Constitucionales, $2^{\mathrm{a}}$ ed.

Arancibia MatTar, Jaime (2010): "The intensity of judicial review in the commercial context: deference and proportionality", en Christopher Forsyth, Mark Elliott, Swati Jhaveri, Michael Ramsden, and Anne Scully Hill (Editores): Effective judicial review, Oxford, Oxford University Press, 287-299.

ARNOLD, Rainer (2009): "Le juge constitutionnel et la proportionnalité", en $A n$ nuaire International de Justice Constitutionnelle XXV, Institut Louis Favoreu, Marseille, 115 - 122.

ARnold, Rainer (2010): Constitutions et droit pénal, Rapport allemand, XXVIe Table ronde international, Aix-en-Provence, 95-108.

Bermúdez Soto, Jorge (2010): Derecho Administrativo General, Santiago, AbeledoPerrot.

Bernal Pulido, Carlos (2007): El principio de proporcionalidad y los derechos fundamentales, Centro de Estudios Políticos y Constitucionales, Madrid, $3^{\text {a }}$ ed.

Bon, P. y Maus, D. (coordinadores) (2008): Les grandes décisions des cours constitutionnelles européennes, Paris, Dalloz.

Bertelsen Simonetti, Soledad (2010): "Métodos de solución de conflictos entre derechos fundamentals", en Cuadernos del Tribunal Constitucional 42, 13108.

CHRISTOFFersen, Jonas (2009): Fair balance: proportionality, subsidiarity and primarity in the European Convention on Human Rights, Leiden, Martinus Nijhoff Publishers.

Cianciardo, Juan (2000): El conflictivismo en los derechos fundamentales, Pamplona, EUNSA. 2000.

Cianciardo, Juan (2004): El principio de proporcionalidad. Del debido proceso sustantivo al moderno juicio de proporcionalidad, Buenos Aires, Edit. Ábaco de Rodolfo Depalma.

Dе Отто, Ignacio (1998): "La regulación del ejercicio de los derechos y libertades. La garantía de su contenido esencial en el artículo 53.1 de la Constitución", en Martín Retortillo y de Otto, Derechos fundamentales y Constitución, Civitas, Madrid. 
DwOrKIn, Ronald (1984): Los derechos en serio, Barcelona, Ariel.

ELLIOT, Mark (2000): "Fundamental rights as interpretative constructs: The constitutional logic of the Human Rights Act 1998", en Forsyht, Christopher (Editor): Judicial Review \& the Constitution, Oxford, Hart Publishing, 267-288.

FernándeZ GonzÁlez, Miguel Angel (2000): "Principios constitucionales de proporcionalidad y justicia en materia tributaria" en Revista Chilena de Derecho, Vol. 27, No 2, 357-371.

Fernández GonzÁlez, Miguel Ángel (2001): Principio constitucional de igualdad ante la ley, ConoSur, Santiago.

Fernández Nieto, Josefa (2008): Principio de proporcionalidad y derechos fundamentales: una perspectiva desde el Derecho Público común Europeo, Madrid, Universidad Rey Juan Carlos.

GARCÍA, Gonzalo (2004): La reserva legal de los derechos constitucionales: ¿Poder Legislativo contra la Administración ?, Santiago, Universidad Alberto Hurtado.

GuILlENCHMIDT, Jacqueline (2010) : "Le contrôle du principe de proportionnalité dans la jurisprudence du Conseil constitutionnel français", en La proportionnalité dans la jurisprudence constitutionnelle. 5 e Conférence des Chefs d'institution de l'Association des Cours constitutionnelles ayant en partage l'usage du francais, Association des Cours Constitutionnelles ayant en Partage l'Usage du Français, Bulletin No 9, 27-34.

HÄBERLE, Peter (2003): La garantía del contenido esencial de los derechos fundamentales, Madrid, Dykinson.

IsAaC, Guy (2000): Manual de Derecho comunitario general, Ariel, Barcelona, 5a ed.

IsLer Soto, Carlos (2011): "Una crítica finnisiana al principio de proporcionalidad", en Ius Publicum 26, 31-52.

KRAFT, Ingo (2007): "Der Grundsatz der Verhältnismäßigkeit im deutschen Rechtsverständnis", en Bayerische Verwaltungsblätter (BayVBl) 19, 577 y ss.

Mcbride, Jeremy (1999): "Proportionality and the European Convention on Human Rights", en Ellis, Evelyn (Editora): The principle of proportionality in the laws of Europe, Oxford, Hart. 1999, 23-35.

Medina Quiroga, Cecilia y Nash Rojas, Claudio (2007): Sistema Interamericano de Derechos Humanos: Introducción a sus Mecanismos de Protección, Santiago, Centro de Derechos Humanos de la Facultad de Derecho de la Universidad de Chile.

Nogueira Alcalá, Humberto (2008): Derechos fundamentales y garantías constitucionales, Santiago, Librotecnia, Tomos I y II. 
Nogueira Alcalá, Humberto (2010): "El principio de proporcionalidad y su aplicación en Sudamérica por la jurisdicción constitucional, con especial mención al Tribunal Constitucional chileno", en Carbonell, Miguel (Coordinador): El principio de proporcionalidad en la interpretación jurídica, Santiago, Librotecnia, 353-403.

Pereira Menaut, Antonio Carlos (2003): Sistema político y constitucional de Alemania. Una introducción, Santiago de Compostela, Tórculo Edicións.

Pereira Menaut, Antonio Carlos (2006): Teoría constitucional, Santiago, LexisNexis.

Pereira Menaut, Antonio Carlos (2011): Código Constitucional de la Unión Europea, Santiago de Compostela, Andavira Editora, 765.

Ramos Tavares, André (2006): Curso de Direito Constitucional, São Paulo, Editora Saravia, $4^{\mathrm{a}} \mathrm{ed}$.

SAPAG, Mariano A. (2008): "El principio de proporcionalidad y de razonabilidad como límite constitucional al poder del estado: Un estudio comparado", en Dikaion 17, 157-198.

Serna, Pedro (1994): "Derechos fundamentales: el mito de los conflictos. Reflexiones teóricas a partir de un supuesto jurisprudencial sobre intimidad e información", en Humana Iura (No 4), pp. 197-234.

Serna, Pedro y Toller, Fernando (2000): La interpretación constitucional de los derechos fundamentales. Una alternativa a los conflictos de derechos, Buenos Aires, La Ley.

Stone SweEt, Alec y Keller, Helen (2008): "The reception of the ECHR in national legal orders", en Keller, Helen y Stone Sweet, Alec (Editores), A Europe of rights, Oxford, Oxford University Press, 3-28.

ThOmas, Robert (2000): Legitimate expectations and proportionality in Administrative law, Oxford, Hart.

\section{JURISPRUDENCIA CITADA}

Tribunal Constitucional Federal de Alemania, sentencias:

- Vol. 2, p. 1

- Vol. 3, pp. 383, 399

- Vol. 7, pp. 377, 397-413

- Vol. 13, pp. 97, 104, 115

- Vol. 16, pp. 194, 202-203

- Vol. 17, pp. 108, 117

- Vol. 17, pp. 232, 242

- Vol. 19, pp. 342, 347-352 
- Vol. 125, pp. 260, 278, 291, 316, 325, 356, 363, 366

- Vol. 125, pp. 260

- Vol. 125, pp. 360, 328

Tribunal de Justicia de la Unión Europea, sentencias:

- Costa/Enel, de 15 de julio de 1964 (asunto 6/64)

- Administration des finances de l'Etat/Societé anonyme Simmenthal, de 9 de marzo de 1978 (asunto 106/77)

- N.V. Algemene Transport- en Expeditie Onderneming Van Gend Loos/Administration Fiscale Néerlandaise, de 5 de febrero de 1963 (asunto 26/62)

- Internationale Handelsgesellschaft mbH/Einfurh- und Vorratsstelle für Getreide und Futtermittel, de 17 de diciembre de 1970 (asunto 11/70)

- Nold, Kohlen-und BaustoffgroBhandlung/Comisión, de 14 de mayo de 1974 (asunto 4/73)

- S.A. Roquette Frères/Consejo, de 29 de octubre de 1980 (asunto 138/79)

- Parti Ecologiste-"Les verts"/Parlamento Europeo, de 23 de abril de 1986 (asunto 294/83)

- Caso Hauer, de 13 de diciembre de 1979 (asunto 44/79)

- Caso Wachauf de 13 de Julio de 1989 (asunto 5/88)

- Rau/Comunidad Económica Europea, de 11 de marzo de 1987 (asuntos 279, 280, 285 y 286/84).

- Caso de la mantequilla, de 28 de junio de 1990 (asunto C-174/89)

- Caso de los plátanos, de 5 de octubre de 1994 (asunto C-280/93).

Tribunal Europeo de Derechos Humanos, sentencias:

- Niemietz con Alemania de 6 de diciembre de 1992 (asunto 13710/88)

- Valenzuela Contreras con España de 30 de julio de 1998 (asunto 58/1997/842/1048).

- Pretty con Reino Unido de 29 de abril de 2002 (asunto 2346/02).

- Von Hannover con Alemania de 24 de junio de 2004 (asunto 59320/00) y sentencia de 7 de febrero de 2012 (asuntos 40660/08 y 60641/08)

- Kokkinakis con Grecia de 25 de mayo de 1993 (asunto 14307/88). Hassan y Tchaouch con Bulgaria de 26 de octubre de 2000 (asunto 30985/96)

- Leyla Sahin con Turquía de 10 de noviembre de 2005 (asunto 44774/98)

- Lautsi con Italia de 18 de marzo de 2011 (asunto 30814/06)

- Handyside con Reino Unido de 7 de diciembre de 1976 (asunto 5493/72) 
- Lingens con Austria de 8 de julio de 1986 (asunto 5493/72)

- Otto Preminger-Institut con Austria de 20 de septiembre de 1994 (asunto 13470/87)

- Wingrove con Reino Unido de 25 de noviembre de 1996 (asunto 19/1995/525/611)

- Fressoz y Roire con Francia 21 enero de 1999 (asunto 29183/95)

- Fikret Cetin con Turquía de 13 de febrero de 2003 (asunto 24829/03)

- Mestri con Italia de 17 de febrero de 2004 (asunto 39748/98)

- Ezelin con Francia de 26 de abril de 1991 (asunto 11800/85)

- Partido Comunista Unificado de Turquía y otros con Turquia de 13 de enero de 1998 (asunto 133/1996/752/951)

- Chassagnou y otros con Francia de 29 de abril de 1999 (asuntos 25088/94, $28331 / 95$ y $28443 / 95)$

- Refah Partisi y otros con Turquía de 13 de febrero de 2003 (41340/98, 41342/98, 41343/98 y $41344 / 98)$

Corte Interamericana de Derechos Humanos, opiniones consultivas y sentencias:

- Opinión Consultiva 5/85

- Opinión Consultiva 8/87

- Caso Usón Ramírez v. Venezuela, sentencia de 20 de noviembre de 2009

- Caso Kimel v. Argentina, sentencia de 2 de mayo de 2008

- Caso López Mendoza v. Venezuela, sentencia de 1 de septiembre de 2011

- Caso Ricardo Canese v. Paraguay, Sentencia de 31 de agosto de 2004

- Caso Castañeda Gutman v. Estados Unidos Mexicanos, sentencia de 6 de agosto de 2008

- Caso López Mendoza v. Venezuela, sentencia de 1 de septiembre de 2011

Sentencias Tribunales Constitucionales Europeos:

- Francia: sentencia de 21 de febrero 2008

- Bélgica: sentencia 23/89, de 13 de octubre de 1989

- Polonia: sentencia 11/98 de 2000, de 12 de enero de 2000

- España: STC 154/2002, de 18 de Julio de 2002

Tribunal Constitucional de Chile, sentencias roles $N^{o}$ :

- 43-87, de 16 de enero de 1987, Control de constitucionalidad respecto del proyecto de ley orgánica constitucional de partidos políticos, en página elec- 
trónica Tribunal Constitucional http://www.tribunalconstitucional.cl/wp/ ver.php?id=566

- 280-98, de 16 de septiembre de 1998, Requerimiento de Diputados acerca del proyecto de ley que rebaja la tasa de los aranceles a las importaciones e introduce modificaciones a otras normas tributarias y económicas, en página electrónica Tribunal Constitucional http://www.tribunalconstitucional.cl/wp/ ver.php?id $=338$

- 541-06, de 13 de julio de 2006, Requerimiento de inaplicabilidad presentado por la Corte de Apelaciones de Santiago respecto del inciso primero del artículo 42 del DFL No 164, de 1991(Ley de Concesiones), en relación a la causa caratulada "Autopista Central S.A. con Servicio de Mecánica Mantención Track S.A.”, Rol No 2.097-2006, seguida ante la Corte de Apelaciones de Santiago, en página electrónica Tribunal Constitucional http://www.tribunalconstitucional. $\mathrm{cl} / \mathrm{wp} / \mathrm{ver}$.php?id=129.

- 546-06, de 21 de julio de 2006, Requerimiento de inaplicabilidad por inconstitucionalidad presentado por Jacobo Kravetz Miranda, respecto del artículo 30 del Decreto Ley No 3.538, en la causa Rol No 9.059-06 seguida ante el $8^{\circ}$ Juzgado de Letras en lo Civil de Santiago, en página electrónica Tribunal Constitucional http://www.tribunalconstitucional.cl/wp/ver.php?id=127.

- 755-07, de 22 de marzo de 2007, Requerimiento de inaplicabilidad por inconstitucionalidad presentado por Sergio Toloza Rodríguez y el Presidente del Colegio de Abogados de Chile respecto del artículo 595 del Código Orgánico de Tribunales, en los autos sobre apelación de protección, caratulados "Sergio Toloza Rodríguez con Juez de Familia de Osorno", de que conoce la Corte Suprema, bajo el Rol No 6.626-2006, en página electrónica Tribunal Constitucional http://www.tribunalconstitucional.cl/wp/ver.php?id=906.

- 790-07, de 25 de mayo de 2007, Requerimiento de inaplicabilidad presentado por Fernando Coloma Reyes y otros respecto del artículo $4^{\circ}$ de la Ley No 18.549 y del artículo 29 de la Ley No 18.669 en la causa cartulada "Lagos, Hipólito y otros con INP”, Rol No 18.828-06, seguida ante el 7o Juzgado Civil de Santiago, en página electrónica Tribunal Constitucional http://www. tribunalconstitucional.cl/wp/ver.php?id=19.

- 792-07, de 30 de mayo de 2007, Requerimiento de inaplicabilidad presentado por Hernán Pfeifer Frenz y Paulina Alegría Madrid y Carmen Polanco Lazo, respecto de la segunda frase del inciso primero del artículo 171 del Código Sanitario, en los autos caratulados "Pfeifer Frenz con Instituto de Salud Pública", Rol No 14.980-2006, en el 11 Juzgado Civil de Santiago, en página electrónica Tribunal Constitucional http://www.tribunalconstitucional.cl/wp/ ver.php?id=728. 
- 976-07, de 2 de octubre de 2007, Requerimiento de inaplicabilidad por inconstitucionalidad presentado por Silvia Peña Wasaff respecto del artículo 38 ter de la Ley No 18.933, conocida como Ley de Isapres, en recurso de protección contra Isapre ING Salud S.A., Rol de Ingreso No 4972-2007, de la Corte de Apelaciones de Santiago, en página electrónica Tribunal Constitucional http:// www.tribunalconstitucional.cl/wp/ver.php?id=957.

- 1.046-08, de 3 marzo de 2008, Requerimiento de inaplicabilidad de Sociedad Sergio Andrés Concha San Martín y Otro respecto de la parte final del inciso primero del artículo 171 del Código Sanitario, en la causa caratulada "Concha San Martín, Sergio Andrés, con Fisco", en página electrónica Tribunal Constitucional de la Corte de Apelaciones de Concepción, http://www. tribunalconstitucional.cl/wp/ver.php?id=971.

- 1061-08, de 17 de abril de 2008, Requerimiento de inaplicabilidad de Hernán Pfeifer Frenz, Paulina Alegría Madrid y Carmen Polanco Lazo respecto de la segunda frase, del inciso primero, del artículo 171 del Código Sanitario, en causa caratulada "Pfeifer Frenz, Hernán, y otras con Instituto de Salud Pública”, Rol C-7.770-2008, del 11º Juzgado Civil de Santiago.

- 1138-08, de 26 de mayo de 2008, Requerimiento de inaplicabilidad por inconstitucionalidad presentado por Maryem Darwiche Espinoza respecto del inciso primero del artículo 595 del Código Orgánico de Tribunales, en los autos sobre cobro de honorarios profesionales, caratulados "Darwiche Espinoza, Maryem con Fisco de Chile", de que conoce el Tercer Juzgado de Letras de Iquique, bajo el Rol No 1.505-2008, en página electrónica Tribunal Constitucional http://www.tribunalconstitucional.cl/wp/ver.php?id=1008.

- $1.140-08$, de 2 de junio de 2008, Requerimiento de inaplicabilidad por inconstitucionalidad deducido por María José Arancibia Obrador respecto del artículo 595 del Código Orgánico de Tribunales, en página electrónica Tribunal Constitucional http://www.tribunalconstitucional.cl/wp/ver.php?id=1091.

- 1.170-08, de 26 de agosto de 2008, Control de constitucionalidad del proyecto de ley, que establece una excepción a la inhabilidad establecida en la letra b) del artículo 54 de la Ley No 18.575, Orgánica Constitucional de Bases Generales de la Administración del Estado, con el objeto de permitir el ingreso de parientes y familiares al Servicio Exterior (boletín 4313-06), en página electrónica Tribunal Constitucional http://www.tribunalconstitucional. $\mathrm{cl} / \mathrm{wp} / \mathrm{ver} \cdot \mathrm{php}$ ?id=997.

- 1.182-08, de 22 de julio de 2008, Requerimiento de inaplicabilidad de Patricio Enrique Máximo Paredes Rogat y Ernesto Humberto Amaya Mancilla respecto del artículo $4^{\circ}$ de la Ley No 19.260, en la causa Rol No 7.314-2003, sobre 
juicio ordinario por cobro de pensiones no contributivas, seguido ante el $17^{\circ}$ Juzgado Civil de Santiago y actualmente en la Corte Suprema, por recurso de casación en contra de la sentencia de segunda instancia, Rol No 2.859-2008, en página electrónica Tribunal Constitucional, http://www.tribunalconstitucional.cl/wp/ver.php?id=1046.

- 1.193-08, de 1 de agosto de 2008, Requerimiento de Juan González Alvarez y José Del Carmen Flores respecto del artículo 4o de la Ley No 19.260, en la causa Rol No 2.573-2004, sobre juicio ordinario por cobro de pensiones no contributivas, del $13^{\circ}$ Juzgado Civil de Santiago y actualmente en la Corte Suprema, bajo el Rol No 2.911-2008, en página electrónica Tribunal Constitucional, http://www.tribunalconstitucional.cl/wp/ver.php?id=1047.

- 1.201-08, de 13 de agosto de 2008, Requerimiento de inaplicabilidad de Evangelina Sanhueza Miranda y Rosa María Tapia Soria respecto del artículo $4^{\circ}$ de la Ley No 19.260, en la causa Rol No 6.082-2003, seguido ante el 30 Juzgado Civil de Santiago y actualmente en la Corte Suprema, bajo el Rol No 3.708-2008, en página electrónica Tribunal Constitucional, http://www. tribunalconstitucional.cl/wp/ver.php?id=1068.

- 1.204-08, de 20 de agosto de 2008, Requerimiento de inaplicabilidad por inconstitucionalidad de Sociedad Constructora SIGMA Limitada respecto del artículo 1891 del Código Civil en la causa Rol No 5.817-2008del Vigésimo Cuarto Juzgado Civil de Santiago, caratulada "Sociedad Constructora Sigma Limitada con Banco de Chile", en página electrónica Tribunal Constitucional, http://www.tribunalconstitucional.cl/wp/ver.php?id=1152.

- 1.218-08, de 27 de agosto de 2008, Requerimiento de inaplicabilidad por inconstitucionalidad de María Ximena Osorio Sagredo respecto del artículo 38 ter de la Ley No 18.933 -introducido por la Ley No 20.015-, que actualmente corresponde al artículo 199 del D.F.L. (Ministerio de Salud) No 1, de 2005, en la causa Rol No 10.913-2008, de la que conoce actualmente, como árbitro arbitrador, el Intendente de Fondos y Seguros de Salud, en página electrónica Tribunal Constitucional, http://www.tribunalconstitucional.cl/ $\mathrm{wp} / \mathrm{ver}$.php?id=1182.

- 1.253-08, de 13 de octubre de 2008, Requerimiento de inaplicabilidad deducido por Arco Arquitectura y Construcción Limitada respecto del inciso primero del artículo 171 del Código Sanitario, en la causa Rol No 3.2402008, caratulada "Arco Arquitectura y Construcción Limitada con Secretaría Regional Ministerial de Salud de Valparaíso", del Tercer Juzgado Civil de Valparaíso, en página electrónica Tribunal Constitucional, http://www.tribunalconstitucional.cl/wp/ver.php?id=1094. 
- 1254-08, de 15 de octubre de 2008, Requerimiento de inconstitucionalidad del Presidente del Colegio de Abogados de Chile A.G., señor Enrique Barros Bourie, en representación de dicha entidad respecto del texto íntegro del artículo 595 del Código Orgánico de Tribunales, en página electrónica Tribunal Constitucional, http://www.tribunalconstitucional.cl/wp/ver.php?id=1197.

- $1.260-08$, de 22 de octubre de 2008, Requerimiento de inaplicabilidad por inconstitucionalidad deducido por María Teresa Lorca Morales respecto del inciso segundo del artículo $4^{\circ}$ de la Ley No 19.260, en la causa Rol No 27.808-2007, del Décimo Octavo Juzgado Civil de Santiago, caratulada "Lorca Morales, María Teresa, con Instituto de Normalización Previsional", en página electrónica Tribunal Constitucional, http://www.tribunalconstitucional.cl/wp/ver.php?id=1200.

- 1.262-08, de 23 de octubre de 2008, Requerimiento de inaplicabilidad por inconstitucionalidad de Sociedad de Servicios y Asesorías Swan (Chile) S.A. respecto de la parte final del inciso primero, del artículo 171 del Código Sanitario, en causa Rol No 26.220-2008 del Décimo Sexto Juzgado Civil de Santiago, caratulada "Sociedad de Servicios y Asesorías SWAN S.A. con Secretaría Regional Ministerial de Salud de la Región Metropolitana”, en página electrónica Tribunal Constitucional, http://www.tribunalconstitucional.cl/wp/ver.php?id=1118.

- 1.273-08, de 24 de noviembre de 2008, Requerimiento de inaplicabilidad de María Angélica Valenzuela Márquez, respecto del artículo 38 ter de la Ley No 18.933, en recurso de protección No 9451-2008, de la Corte de Apelaciones de Santiago, en página electrónica Tribunal Constitucional http://www. tribunalconstitucional.cl/wp/ver.php?id=1335.

- 1.279-08, de 28 de noviembre de 2008, Requerimiento de inaplicabilidad por inconstitucionalidad de Manuel Enrique Valdés Valdés en su calidad de administrador de la Comunidad Edificio Santiago Centro y en su representación, respecto de la parte final del inciso primero, del artículo 171 del Código Sanitario, en causa Rol C-25.623-2008, caratulada "Comunidad Edificio Santiago Centro con Secretaría Regional Ministerial de Salud de la Región Metropolitana y Fisco de Chile", del Segundo Juzgado Civil de Santiago, en página electrónica Tribunal Constitucional http://www.tribunalconstitucional. $\mathrm{cl} / \mathrm{wp} / \mathrm{ver} \cdot \mathrm{php}$ ?id=1117.

- $\quad$ 1.287-08, de 16 de diciembre de 2008, Requerimiento de inaplicabilidad por inconstitucionalidad de Pedro Fernández Bitterlich, respecto del artículo 38 ter de la ley No 18.933, en Rol No 7.952-2008, de la Corte de Apelaciones de Santiago, en página electrónica Tribunal Constitucional http://www.tribunalconstitucional.cl/wp/ver.php?id=1219. 
- $\quad$ 1.307-09, de 15 de enero de 2009, Acción de inaplicabilidad por inconstitucionalidad de Pauline Jeanneret Elsner, respecto del artículos 22 y 25, No 2 de la Convención de Varsovia, en página electrónica Tribunal Constitucional http://www.tribunalconstitucional.cl/wp/ver.php?id=1741.

- $\quad 1.345-09$, de 10 de marzo de 2009, Pronunciamiento de oficio sobre la inconstitucionalidad de las expresiones: "Para dar curso a ellos se exigirá que el infractor acompañe el comprobante de haber pagado la multa", contenidas en el inciso primero del artículo 171 del Código Sanitario, en página electrónica Tribunal Constitucional http://www.tribunalconstitucional.cl/wp/ver.php?id=1146.

- 1.361-09, de 7 de abril de 2009, Requerimiento de 10 Senadores de la República en contra de la constitucionalidad de determinados artículos del proyecto de ley que establece la Ley General de Educación (LEGE), en página electrónica Tribunal Constitucional http://www.tribunalconstitucional.cl/wp/ver. php?id=1136.

- $\quad$ 1.399-09, de 29 de mayo de 2009, Acción de inaplicabilidad por inconstitucionalidad del inciso final del No 1 del artículo 42 de la Ley sobre Impuesto a la Renta, en el Rol ingreso No 238-2009 ante la Corte de Apelaciones de Valparaíso y que con fecha 29 de mayo de 2009 se interpuso un recurso de casación de fondo ante la Corte Suprema en contra de la sentencia del rol ya mencionado, en página electrónica Tribunal Constitucional http://www. tribunalconstitucional.cl/wp/ver.php?id=1611.

- 1.414-09, de 18 de junio de 2009, Requerimiento de inaplicabilidad por inconstitucionalidad de Ingeniería y Construcción Pesada Limitada, respecto del artículo 43 numeral $1^{\circ}$ de la Ley No 18.175, en Rol C- 9.909-2008 del Quinto Juzgado de Letras en lo Civil de Santiago, en página electrónica Tribunal Constitucional http://www.tribunalconstitucional.cl/wp/ver.php?id=1559.

- 1448-09, de 27 de julio de 2009, Requerimiento de inaplicabilidad por inconstitucionalidad de Sindicato de Trabajadores de la Empresa Portuaria de Coquimbo, respecto del artículo $31^{\circ}$ inciso final del DFL No 1 del Ministerio de Economía fomento y Reconstrucción, y del DL No 211 de 1973, en Rol de ingreso No 3.733-2009 de la Corte Suprema, en página electrónica Tribunal Constitucional, http://www.tribunalconstitucional.cl/wp/ver.php?id=1522.

- 1.463-09, de 18 de agosto de 2009, Requerimiento de inaplicabilidad por inconstitucionalidad de Gerard Philippe Bordachar Sotomayor y Otros, respecto del artículo 2.331 del Código Civil, en ingreso No 2.517-2008 en recurso de protección de la Corte de Apelaciones de Santiago, y en Rol de ingreso No 5.034-2005 del 18 Juzgado Civil de Santiago, en página electrónica Tribunal Constitucional http://www.tribunalconstitucional.cl/wp/ver. php?id=1571. 
- $\quad$ 1.584-09, de 31 de diciembre de 2009, Requerimiento de inaplicabilidad por inconstitucionalidad de Roberto Oetiker Luchsinger, Egon Hoffmann Soto y otros, respecto del artículo 317 del Código Penal en causa ruc 08001025768 del Tribunal de Garantía de San Bernardo, en página electrónica Tribunal Constitucional http://www.tribunalconstitucional.cl/wp/ver.php?id=1400.

- 1.638-10, de 12 de marzo de 2010, Requerimiento de inaplicabilidad por inconstitucionalidad de Hugo Villanueva Cruz, respecto del artículo 38 ter de la Ley No 18.933 en Recurso de Protección de ingreso Rol No 479-2010 de la Corte de Apelaciones de Santiago, en página electrónica Tribunal Constitucional http://www.tribunalconstitucional.cl/wp/ver.php?id=1733.

- 1.679-10, de 7 de abril de 2010, Acción de inaplicabilidad por inconstitucionalidad de Felipe Camiroaga Fernández, respecto del artículo 2331 del Código Cívil, en los autos Rol No 4.502-2009, sobre recurso de apelación y casación en la forma interpuestos ante la de Apelaciones de Santiago en contra de la sentencia pronunciada por el $10^{\circ}$ Juzgado Civil de Santiago en causa Rol No 14.645 sobre indemnización de perjuicios, en página electrónica Tribunal Constitucional http://www.tribunalconstitucional.cl/wp/ver.php?id=1797.

- 1.710-10, de 27 de abril de 2010, Proceso de inconstitucionalidad iniciado de oficio por el Tribunal Constitucional, con relación al artículo 38 ter de la Ley No 18.933, en página electrónica Tribunal Constitucional, http://www. tribunalconstitucional.cl/wp/ver.php?id=1479.

- 1.741-10, de 3de junio de 2010, Acción de inaplicabilidad por inconstitucionalidad de Gerardo Villegas Millar respecto del artículo 2331 del Código Civil, en los autos Rol No 28.538 sobre juicio ordinario de indemnización de perjuicios seguidos ante el 290 Juzgado Civil de Santiago, en página electrónica Tribunal Constitucional http://www.tribunalconstitucional.cl/wp/ver. php?id $=1795$.

- 1.798-10, de 12 de agosto de 2010, Acción de inaplicabilidad por inconstitucionalidad de Joaquín Godoy Ibáñez respecto del artículo 2331 del Código Civil, en los en los autos Rol No 8.340-2009 sobre juicio ordinario de indemnización de perjuicios sustanciados ante el Ministro de Fuero Juan Eduardo Fuentes Belmar de la Corte de Apelaciones de Santiago, en página electrónica Tribunal Constitucional http://www.tribunalconstitucional.cl/wp/ ver.php?id=1819.

- 1.801-10, de 16 de agosto de 2010, Requerimiento de inaplicabilidad por inconstitucionalidad de la Corte de Apelaciones de Valparaíso respecto del artículo $4^{\circ}$ de la Ley No $^{\circ} 19$. 531, sustituido por el artículo $1^{\circ}$ de la Ley No 20.224, en los autos Rol No 300-2010 sobre recurso de protección inter- 
puesto ante la Corte de Apelaciones de Valparaíso en contra de la Corporación Administrativa del Poder Judicial, en página electrónica Tribunal Constitucional http://www.tribunalconstitucional.cl/wp/ver.php?id=1837.

- $1.812-10$, de 1 de septiembre de 2010, Requerimiento de inconstitucionalidad presentado por Isapre Cruz Blanca S.A. respecto del artículo $7^{\circ}$ del Auto Acordado sobre tramitación y fallo del recurso de protección de garantías constitucionales de la Corte Suprema, de 27 de junio de 1992, en los autos Rol No 3.000-2010 sobre recurso de protección interpuesto ante la Corte de Apelaciones de Santiago (Secretaría Criminal), en página electrónica Tribunal Constitucional http://www.tribunalconstitucional.cl/wp/ver.php?id=2127.

- 1.816-10, de 1 de septiembre de 2010, Requerimiento de inconstitucionalidad presentado por Isapre Cruz Blanca S.A. respecto del artículo $7^{\circ}$ del Auto Acordado sobre tramitación y fallo del recurso de protección de garantías constitucionales de la Corte Suprema, de 27 de junio de 1992, en los autos Rol No 2.565-2010 sobre recurso de protección interpuesto ante la Corte de Apelaciones de Santiago (Secretaría Criminal), en página electrónica Tribunal Constitucional http://www.tribunalconstitucional.cl/wp/ver.php?id=2123.

- $\quad$ 1.817-10, de 1 de septiembre de 2010, Requerimiento de inconstitucionalidad de Isapre Cruz Blanca S.A. respecto del artículo $7^{\circ}$ del Auto Acordado sobre tramitación y fallo del recurso de protección de garantías constitucionales de la Corte Suprema, de 27 de junio de 1992, en los autos Rol No 2.270-2010, sobre recurso de protección interpuesto ante la Corte de Apelaciones de Santiago (Secretaría Criminal), en página electrónica Tribunal Constitucional http://www.tribunalconstitucional.cl/wp/ver.php?id=2125.

- 1.988-11, de 21 de mayo de 2011, Requerimiento presentado por 17 Senadores respecto de la inconstitucionalidad del Convenio Internacional para la Protección de Obtenciones Vegetales (UPOV-91). Boletín No 6426-10, en página electrónica Tribunal Constitucional http://www.tribunalconstitucional. $\mathrm{cl} / \mathrm{wp} / \mathrm{ver} \cdot \mathrm{ph}$ ? id=1987. 